\title{
"Dípteros da subfamília Phlebotominae: padronização da técnica imunoenzimática (ELISA) para detecção de fontes alimentares sanguíneas"
}

\author{
Iole Arumi Sei
}

Dissertação apresentada ao Programa de PósGraduação em Saúde Pública da Faculdade de Saúde Pública da Universidade de São Paulo para obtenção do título de Mestre em Saúde Pública.

Área de Concentração: Epidemiologia Orientadora: Prof ${ }^{a}$ Dra. Eunice Aparecida Bianchi Galati

São Paulo

2009 


\section{Agradecimentos}

A Deus, que me protegeu e iluminou meu caminho;

À Profa. Dra. Eunice Aparecida Bianchi Galati; pela orientação, confiança, paciência e apoio neste trabalho;

Às minhas amigas e mestras Dra. Maria Esther de Carvalho, Dra. Izilda Curado, Dra. Ana Maria Ribeiro Duarte e Dra. Maria Stela Branquinho Berdoin, pesquisadoras da Superintendência de Controle de Endemias - SUCEN e Dra. Ana Maria Marassá do Instituto Adolfo Lutz, pela colaboração, incentivo e dedicação nesta jornada;

Às amigas, Julia, Rosângela, Benê, Celiane, Carla da SUCEN, Maria Dulce Bianchi Rosa e Edna Maria Fátima Bueno funcionárias da Faculdade de Saúde Pública e aos pós-graduandos da Faculdade de Saúde Pública,José Carlos Moschim e Fredy Galvis Ovallos, por me ajudarem na pesquisa de forma ativa.

Ao Profo.Dr. Mauro Toledo Marrelli por permitir o uso do Laboratório de Entomologia em Saúde Pública/Biologia Analítica II da Faculdade de Saúde Pública/USP para realização do ELISA;

À Superintendência de Controle de Endemias - SUCEN por ter permitido a realização deste trabalho. 
SEI IA. Dipteros da Sub-Família Phlebotominae: padronização da técnica imunoenzimática (ELISA) para deteç̧ão de fontes alimentares sanguíneas. São Paulo, 2009. [Dissertação de Mestrado - Faculdade de Saúde Pública da USP]

\section{RESUMO}

O estudo do sangue ingerido pelos insetos tem evidentes significados ecológico e epidemiológico, pois pode auxiliar na identificação dos animais possivelmente envolvidos na manutenção de ciclos enzoóticos de agentes etiológicos de doenças. Oferece, portanto, subsídios para a indicação de potenciais reservatórios desses agentes, assim como o papel protetor que certos animais poderiam desempenhar em relação ao homem em área de transmissão dos mesmos. Dentre os métodos empregados para avaliar o grau de atração exercido por certas fontes de alimento em relação aos vetores e, conseqüentemente, detectar possíveis reservatórios de parasitas transmitidos por tais artrópodos, os sorológicos se destacam. $O$ objetivo deste estudo consistiu-se em padronizar a técnica imunoenzimática (ELISA) de captura adotada por Chow et al. 1993 para mosquitos do gênero Aedes e empregá-la na identificação de sangue ingerido por flebotomíneos, visando a sua implantação em Laboratório de Saúde Pública, para estudos de hábito alimentar destes insetos, em áreas de transmissão de leishmaniose. $O$ teste foi padronizado para a identificação de sangue de fonte: humana, ave, suíno, cão e rato. Para a identificação da reatividade, segundo o tempo de digestão do sangue ingerido, foram utilizadas fêmeas ingurgitadas de flebotomíneos da espécie Nyssomyia intermedia criadas em laboratório, alimentadas com sangue humano e mortas em intervalos de $0,2,4,6,8,10,12,24$ e 36 horas pós-repasto. Posteriormente, 232 fêmeas, ingurgitadas ou não, de flebotomíneos silvestres foram testadas. Foi detectado sangue ingerido no abdômen das fêmeas até 36 horas pós-repasto. Das amostras de fêmeas silvestres, $23,3 \%$ foram reagentes a algum tipo das fontes especificadas: $13,8 \%$ para ave $(13,8 \%)$, humano $(5,17 \%)$, suíno $(4,3 \%)$, rato $(2,2 \%)$ e cão $(1,7 \%)$. Repasto misto (rato e humano) foi detectado em $1,7 \%$ das amostras. A técnica ELISA indireta de captura padronizada neste estudo foi capaz de detectar pequenas quantidades de sangue ingerido por fêmeas de flebotomíneos e provou ser um teste de alto rendimento e de fácil reprodutibilidade, tornando possivel sua aplicação em laboratórios de Saúde Pública.

Descritores: hábito alimentar, vetores, Phlebotominae, técnica imunoenzimática (ELISA) 
SEI IA. Diptera of sub-family Phlebotominae: standardization of Enzyme linked immunosorbent assay (ELISA) for detection of blood feeding sources. São Paulo, 2009. [Master Thesis - School of Public Health of University of São Paulo]

\section{SUMMARY}

Studies of the contents of blood-sucking insect digestive tracts have obvious ecological and epidemiological significance since they aim at the identification of vertebrates which can possibly be involved in the maintenance of the enzootic and epidemiological cycles of etiological agents. On the basis of such information it is possible to find out which vertebrate animal species are acting as reservoirs and, on the other hand, which vertebrates are protecting humans from infections. The immunological methods stand out as means to assess the degrees of attraction exerted by certain animal sources of food (potential reservoirs) towards vectors. The aim of this study was to standardize the Enzyme Linked Immunosorbent Assay (ELISA) as used by Chow et al, 1993 originally applied to the identification feeding habits of Aedes mosquitoes, for its use in the Public Health Laboratories to identify ingesta of phlebotomines captured in areas with American cutaneous leishmaniasis transmission. The test was standardized for the identification of the source blood: human, bird, dog, pig and rat. For the reactivity identification by the digestion-time females of Nyssomyia intermedia reared in the laboratory and fed on human and sacrificated at intervals of $0,2,4,6,8,10,12,24$ and 36 hours post-blood meal were used. After, 232 wild females engorged or not were tested. Blood in the abdomen of the females was identified until 36 hours post-feeding. Of the wild samples, $23 \%$ were reactive to some kind of source tested: $13,8 \%$ for bird $(13,8 \%), 5,17 \%$ para human $(5,17 \%)$, pig $(4,3 \%)$, rat $(2,2 \%)$ and dog $(1,7 \%)$. Mixed blood meals (rat and human) were detected in $1,7 \%$ of the samples. The use of indirect capture ELISA proved to be capable of detecting small ingested blood volumes by sand flies and has proved to be a test of high performance and easy to replicate, making possible its application in public health laboratories.

Uniterms - Feeding habits, vectors, Phlebotominae, Enzyme-linked Immunosorbent Essay (ELISA) 


\section{ÍNDICE}

1. INTRODUÇÃO

2. JUSTIFICATIVA

3. OBJETIVOS

3.1 OBJETIVO GERAL

3.2 OBJETIVOS ESPECÍFICOS

4. MATERIAL E MÉTODOS

4.1. Áreas de estudo

4.1.1 Parque Estadual da Serra da Cantareira (PEC)

4.1.2 Município de Cotia

4.1.3 Parque Estadual Turístico do Alto Ribeira (PETAR)

4.2. Procedência dos flebotomíneos submetidos ao teste

4.2.1 Metodologia de capturas entomológicas

4.2.2 Número de espécimes submetido ao teste.

4.3. Avaliação do hábito alimentar de flebotomíneos

4.3.1 Preparo das amostras

4.3.2 Reação imunoenzimática (ELISA)

4.3.2.1 Padronização dos anti-soros para identificação do sangue ingerido por dípteros da Subfamília Phlebotominae

4.3.2.2 Sensibilidade da técnica ELISA para detecção de sangue em flebotomíneos empregando diferentes volumes de sangue

4.3.2.3 Execução do ELISA com anti-soros humano, de galinha, de suíno, de rato e de cão para verificação do tempo de digestão do sangue nos flebotomíneos 
5. RESULTADOS 28

6. DISCUSSÃO

$\begin{array}{ll}\text { 7. CONCLUSÕES } & 49\end{array}$

8. REFERÊNCIAS BIBLIOGRÁFICAS 50

9. CURRÍCULUM LATTES 


\section{INTRODUÇÃO}

A leishmaniose tegumentar americana (LTA) é parasitose causada por protozoários do gênero Leishmania, transmitida por insetos hematófagos conhecidos genericamente como flebotomíneos. Apesar de ser definida classicamente como uma zoonose de animais silvestres, a LTA acomete a cada ano milhares de indivíduos humanos, caracterizando-se como antropozoonose (SECRETARIA DE ESTADO DA SAÚDE DE SÃO PAULO - CENTRO DE VIGILÂNCIA EPIDEMIOLÓGICA (SES-CVE, 1995). Produz um vasto espectro de formas clínicas, desde úlceras cutâneas benignas até formas mucosas graves e mutilantes. No Brasil é uma doença de notificação compulsória. A infecção por leishmânias tem sido comumente encontrada entre os roedores, marsupiais, edentados e quirópteros, que funcionam como reservatórios sinantrópicos. Canídeos e felídeos também fazem parte da cadeia de transmissão; o homem pode ser afetado secundariamente (LAINSON e SHAW, 1979, 2005).

A ocorrência da doença humana apresenta, pelo menos, duas feições epidemiológicas. A primeira associa-se à entrada do homem na floresta primitiva para exercer atividades profissionais que, em certas ocasiões, resulta em um número expressivo de casos, sugerindo uma epidemia. A segunda está associada ao ambiente no qual a população humana se instala; pós-devastado, porém, com presença de mata remanescente ou residual. Esse ambiente alterado parece funcionar como barreira ecológica para componentes naturais da cadeia de transmissão, o que, talvez, possa explicar menores incidências de casos (GOMES, 1992).

A LTA tem ampla distribuição geográfica. É encontrada desde o sul dos Estados Unidos até o norte da Argentina, não ocorrendo no Chile e no Uruguai. (SESCVE, 1995). No Brasil, há casos em todos os Estados e, nos últimos anos, tem sido registrados em média 28.640 casos novos por ano (MINISTÉRIO DA SAÚDE, 2008). Em São Paulo, a doença, com o passar do tempo, tornou-se rara, devido ao desbravamento e ocupação antrópica das regiões florestais no interior do Estado. Ultimamente tem sido registrada em focos isolados em diversas áreas, aparecendo 
com mais freqüência no Vale do Ribeira e Litoral Norte. Na região do Vale do Ribeira, localizada no litoral sul paulista, não foram registrados casos de LTA até meados da década de 1950. O primeiro registro da doença nessa área é de FORATTINI e OLIVEIRA, em 1957, que descreveram oito casos em moradores de dois bairros rurais do município de Jacupiranga, pertencente à Região Administrativa de Registro. Atualmente essa região é a que possui maiores freqüências da doença (SES-CVE, 2009). Dados recentes mostram que, no ano de 2007 foram registrados 315 casos da doença no Estado de São Paulo, sendo 78 (24,8\%) distribuídos na região da Grande São Paulo. Em 2008, nessa região, esta frequiência teve um pequeno decréscimo, diminuindo para $18,90 \%$ (79 casos dentro do total de 418) (SES-CVE, 2009).

Estudos entomológicos apontam como vetores potenciais de agente da LTA no Estado de São Paulo, as espécies: Nyssomyia intermedia,s.lat., Nyssomyia whitmani, Migonemyia migonei, Lutzomyia pessoai e Pintomyia fischeri (CAMARGO-NEVES et al., 2002).

No Estado de São Paulo, os estudos na década de 40 apontavam para a importância dos flebotomíneos Nyssomyia whitmani e Pintomyia pessoai na veiculação do agente da LTA. Contudo, BARRETTO (1943) chamava a atenção para a regularidade, embora com baixas freqüência de Nyssomyia intermedia s. lat. (à época denominada de Phlebotomus intermedius). .

Os primeiros estudos sobre insetos vetores na região da Serra da Cantareira datam do final da década de 1930 e início da década de 1940, quando BARRETTO (1942, 1943) estudou a biologia de Phlebotominae em condições naturais. Nessa ocasião, o autor encontrou quatro espécies que picavam o homem, predominando: Pintomyia fischeri (69,0\%), Psychodopygus arthuri (17,6\%), Psychodopygus Iloydi $(9,6 \%)$ e Nyssomyia intermedia, s.lat. $(2,1 \%)$. Pi. fischeri, embora ainda não tenha sido encontrada naturalmente infectada por leishmânia, foi infectada experimentalmente por este parasita (PESSÔA e COUTINHO, 1941).

Com o avanço da fronteira agrícola, restringindo as matas do Planalto Paulista a manchas residuais e apenas as matas do sistema da Serra do Mar sendo preservadas, esses ecossistemas passaram a ter maior significado na transmissão 
da infecção, sobretudo as matas do Vale do Ribeira e do vale do rio Mogi-Guaçu e, mais recentemente, do Litoral Norte. Nesses perfis de vegetação, $N y$. intermedia, $s$. lat. passa a ser considerada como um dos principais vetores da endemia e Migonemyia migonei com importância secundária (CAMARGO-NEVES et al., 2002). A identificação de que $\mathrm{Ny}$. intermedia compreendia duas espécies crípticas, $\mathrm{Ny}$. intermedia s. str. e Ny. neivai (Pinto, 1926) foi feita por MARCONDES (1998). Esta última vinha sendo considerada até então como sinônimo júnior da primeira. Ambas são alopátricas nas áreas litorâneas e de Planalto, $\mathrm{Ny}$. intermedia ocorrendo no litoral e Ny. neivai em áreas de Planalto. No Entanto, na Serra do Mar ocorrem em simpatria (MARCONDES et al., 1998; ANDRADE FILHO et al., 2007; GALATI et al., 2009).

No Vale do rio Mogi-Guaçu, no Planalto Paulista, Ny. neivai foi encontrada naturalmente infectada por Leishmania (Viannia) sp. por CASANOVA et al. (1995) e, posteriormente, CASANOVA et al. (2009), a partir de evidências em campo da taxa de sobrevivência, tamanho da população e duração do ciclo gonotrófico, e em laboratório do período de incubação extrínseca em relação a Leishmania braziliensis, inferiram que apenas $1,2-2,6 \%$ das fêmeas potencialmente infectivas estariam vivas para transmitir o parasita, explicando desta forma o padrão de transmissão da LTA em casos esporádicos na área.

Mais recentemente, SARAIVA et al., (2009) encontraram no município de Lassance em Minas Gerais, Ny. neivai naturalmente infectada por Leishmania (L.) infantum chagasi.

Ny. intermedia s. str. foi apontada como vetor do agente da LTA no Rio de Janeiro desde 1922, por ARAGÃO. Mais recentemente, neste Estado, esta espécie, assim como Mg. migonei foram encontradas naturalmente infectada pela Leishmania (Viannia) braziliensis (PITA-PEREIRA et al., 2005).

A análise do conteúdo estomacal de insetos hematófagos é de grande significado ecológico e epidemiológico. Pode ser considerado como indicador, em determinados ambientes, da identidade dos hospedeiros sobre os quais os flebotomíneos adquirem o repasto sanguíneo. Pode oferecer subsídios para a indicação de reservatórios potenciais de leishmânias e do papel protetor do homem 
que certos animais podem desempenhar em áreas de transmissão de parasitos (FERREIRA, 1945).

Os flebotomíneos, assim como muitos outros dípteros hematófagos, necessitam de suprimento de carboidratos, adquiridos na natureza, diretamente da seiva de plantas, assim como néctares (ALEXANDER e USMA, 1994), secreções de afídeos e frutas maduras (CAMERON et al., 1995). As fêmeas complementam com esses nutrientes sua alimentação sanguínea, necessária à oviposição (MAGNARELLI e MODI, 1988; VAN HANDEL, 1984).

Diversas metodologias são empregadas na pesquisa de hábito alimentar de flebotomíneos, desde as que se baseiam em observações visuais, capturas com isca humana ou em armadilhas contendo iscas animais, encontro em abrigos de animais silvestres e domésticos (TEMPELIS, 1975) até as técnicas imunológicas e moleculares.

As técnicas imunológicas para detecção de sangue ingerido em artrópodes são utilizadas há muito tempo (WEITZ, 1960). Entre elas a técnica de precipitina, baseada em reações de precipitação entre um determinado antígeno e antissoro homólogo, foi aplicada para identificar sangue ingerido por mosquito e outros insetos (KING e BULL, 1923; RICE e BARBER, 1935). Com a necessidade de se aumentar a sensibilidade e a especificidade das reações imunológicas, estudos foram realizados com a metodologia dos imunoensaios enzimáticos, comumente conhecidos como ELISA ("Enzyme Linked Immunosorbent Assay"). Nestes, a reação que ocorre entre antígeno e antissoro pode ser revelada por um sistema enzima-substrato que, ao se ligar ao complexo formado, pode desenvolver coloração passível de ser avaliada em colorímetro, em comprimentos de onda específicos. Comparativamente a reações de precipitação, o método de ELISA apresenta custo elevado; entretanto, tem a vantagem de poder utilizar pequenas proporções de repasto sanguíneo, o que facilita o reconhecimento do sangue de múltiplos hospedeiros (BURKOT et al., 1981). O método de ELISA apresenta diferentes formas de identificação no complexo antígenoanticorpo (denominado "conjugado"): direta e indireta (VAZ, 1988). No primeiro caso, o conjugado é ligado diretamente ao antígeno ou ao antissoro. Esse procedimento 
leva ao consumo elevado de reagentes, o que torna o segundo caso, em que 0 complexo antígeno-antissoro é detectado somente após a reação entre esses elementos, mais interessante do ponto de vista prático e econômico.

Em levantamento bibliográfico realizado até 1989, sobre metodologia disponível de identificação de sangue ingerido por insetos transmissores de agentes etiológicos de doenças, SANTOS (1990) destaca a reação imunoenzimática como promissora, dentre as existentes, por apresentar características de sensibilidade e especificidade adequadas aos propósitos epidemiológicos, utilizar pequenas quantidades de amostra e oferecer possibilidade de leitura instrumental, diminuindo erros de interpretação subjetiva de resultados, dentre outras vantagens. Nota-se, a partir dessa década, que surgiram estudos aplicados ao conhecimento de hábitos alimentares de insetos vetores de interesse médico utilizando essa técnica (NIEBYLSKI et al., 1994; SAVAGE et al., 1993; CHOW et al., 1993; RUBIO-PALIS et al., 1994; VICENTIN, 2006). Diversos autores empregaram a técnica imunoenzimática para o conhecimento de fonte alimentar de flebotomíneos (COMER et al., 1994; NGUMBI et al., 1992; YAGHOOBI-ERSHADI et al., 1995). Com o desenvolvimento da técnica imunoenzimática de captura, foi possível detectar a presença de sangue ingerido em pequenas concentrações, em amostras diluídas de diferentes espécies vetoras, tais como nos diminutos dípteros das famílias Ceratopogonidae e Psychodidae (QUINNEL et al., 1992; SERVICE et al., 1986; MARASSÁ et al., 2004, 2006).

Comparações de protocolos de ELISA "sandwich" realizadas por CHOW et al. (1993), em que o antígeno (polivalente) liga-se a um antissoro conhecido, que está aderido à parede de placas e a um antissoro ligado a uma enzima. Esses autores tiveram como objetivo verificar a sensibilidade e a especificidade na deteç̧ão dos sangues dos hospedeiros, utilizando Aedes aegypti, para identificar o sangue do animal contido no estômago das fêmeas ingurgitadas. Detectaram a presença do sangue de: galinha, bovino, cachorro, cavalo, rato, suíno e humano nestes mosquitos, evidenciando a aplicação desse método. 
O sistema avidina-biotina no ELISA indireto para identificar a reatividade do teste em relação à quantidade de sangue no conteúdo estomacal em período pósrepasto em amostras de fêmeas Lutzomyia longipalpis criadas em laboratório e alimentadas em ratos foi utilizado por MARASSÁ et al. (2004). Mais tarde, esses mesmos autores (MARASSÁ et al., 2006) compararam o hábito alimentar de fêmeas de Lu. longipalpis e de Lutzomyia almerioi coletadas em galinheiro, na Serra da Bodoquena, em Mato Grosso do Sul, em relação a aves e ao constatar maior freqüência de reagentes nestas últimas, sugeriram que no ambiente investigado $L u$. longipalpis poderia ser mais eclética em relação à fonte alimentar, com implicações na cadeia epidemiológica das leishmanioses.

Com o desenvolvimento contínuo de novas abordagens metodológicas para identificação de antígenos e de anticorpos, observa-se a conseqũente aplicação em identificação de repasto sanguíneo de insetos vetores. Técnicas de uso corrente em Biologia Molecular ganham destaque. Várias técnicas surgiram a partir do desenvolvimento do diagnóstico de DNA em amostras de sangue fomentadas por pesquisas forenses, baseadas em marcadores moleculares (KOBAYASHI, 2004). KREIKE e KAMPFER (1999), citado por KOBAYASHI (2004) utilizaram PCR para regiões específicas do genoma humano para analisar repastos de mosquitos, verificando a quantidade e a qualidade desse sangue para tipagem individual, auxiliando na identificação de indivíduos envolvidos em crimes.

Diversas técnicas moleculares podem ser empregadas para identificar individualmente o hospedeiro humano. KOBAYASHI (2004) avaliou o impacto de mosquiteiros impregnados com inseticidas na taxa de picadas, assim como na avaliação de comportamento endo e exofílico e variedade de hospedeiros, nos quais o hematófago se alimentou. Essa autora ainda cita outros (TANG e UNNASCH, 1995), que utilizaram PCR-HDA (Polymerase Chain Reaction-Heteroduplex Analysis), técnica baseada em marcadores moleculares para identificação do sangue ingerido de insetos hematófagos e o emprego, por MUKABANA et al. (2002), de citocromo B, um gene mitocondrial que permite identificar a origem do repasto sanguíneo em diferentes espécies de vertebrados, pois possuem padrões facilmente distinguíveis 
uns dos outros, assim como especificidade suficiente para distinguir espécies estreitamente relacionadas.

Embora a tendência para a utilização de técnicas mais sofisticadas represente avanços consideráveis, o teste ELISA ainda pode ser adotado em laboratórios que tenham infra-estrutura disponível para a realização de testes imunoenzimáticos. No mercado, encontram-se cada vez mais disponíveis reagentes para diagnósticos por essa técnica, que permitem a obtenção de resultados confiáveis e reprodutíveis na identificação de fontes alimentares de insetos hematófagos. 


\section{JUSTIFICATIVA}

A preocupação com a participação de reservatórios silvestres, além dos sinantrópicos, possíveis elos entre os ciclos silvestre e doméstico da doença, é manifestada por CAMARGO-NEVES et al. (2006). Neste aspecto, a determinação de fontes de alimentação de flebotomíneos representa importantes subsídios para as análises epidemiológicas, contribuindo para a tomada de decisões sobre atividades de controle de vetores da LTA, motivo pelo qual propusemo-nos a desenvolver o presente trabalho.

Selecionamos a técnica empregada por CHOW et. al. (1993) que, embora realizada para identificação de sangue ingerido por Ae. aegypti, já foi utilizada com modificações para outros mosquitos por VICENTIN (2006) e LAPORTA (2007). Neste trabalho padronizamos a técnica para uso com flebotomíneos. A técnica apresentou diversas vantagens. A primeira pela alta sensibilidade (exige quantidades mínimas de sangue); em seguida na alta especificidade em detectar antígenos de diferentes fontes sanguíneas; a possibilidade de reduzir o número de etapas do teste, o que redunda em diminuição do tempo de realização além da diminuição do custo dos reagentes. Além disso, todo o procedimento é feito em aproximadamente 6 horas; fácil execução; e por último o elevado rendimento - cerca de 80 mosquitos podem ser processados de cada vez, podendo ser executadas para identificação de até 5 fontes.

Assim, uma vez padronizada a técnica para identificação do repasto sanguíneo de flebotomíneo, o próximo passo será implantá-la em Laboratório de Saúde Pública, no caso, da Superintendência de Controle de Endemias - SUCEN, visando a estudos de pesquisa aplicados a focos de interesse em controle e, em próxima etapa, atender a demandas oriundas das áreas endêmicas do Estado. 


\section{OBJETIVOS}

\subsection{GERAL}

Padronizar a técnica imunoenzimática ELISA para determinar hábitos alimentares de flebotomíneos.

\subsection{ESPECÍFICOS}

Padronizar a técnica imunoenzimática ELISA para o estudo do hábito alimentar de flebotomíneos criados em laboratório;

Determinar a reatividade de sangue ingerido por exemplares de flebotomíneos criados em laboratório e alimentados em humano após períodos de $0,2,4,6,8,10,12$, 24 e 36 horas.

Investigar o hábito alimentar de flebotomíneos coletados no campo e observar a possibilidade de obterem o repasto em mais de um hospedeiro no peridomicílio. 


\section{MATERIAL E MÉTODOS}

\section{1 ÁREAS DE ESTUDO.}

As coletas de flebotomíneos submetidos ao teste ELISA foram realizadas em três pontos do Estado de São Paulo: Parque Estadual da Serra da Cantareira (PEC), Bairro Capuava, no município de Cotia e Bairro Serra no município de Iporanga.

\subsubsection{PARQUE ESTADUAL DA SERRA DA CANTAREIRA (PEC)}

O PEC é uma das maiores áreas de mata tropical nativa do mundo situada dentro da região metropolitana, criado pelo Decreto Estadual no 41626 de 1963 e administrado pelo Instituto Florestal da Secretaria do Meio Ambiente do Estado de São Paulo. Com 7.916,52 hectares, cobertos por flora remanescente de Mata Atlântica, é uma das formações vegetais de maior diversidade de espécies em todo o planeta. É caracterizado por uma vegetação ombrófila densa, heterogênea e também por muitas espécies exóticas, como bambu e Pinus. O clima da região é considerado mesodérmico, úmido, sem estiagens com temperatura média no mês mais quente de $22^{\circ} \mathrm{C}$ e no mais frio de $14^{\circ} \mathrm{C}$. O período de chuvas ocorre de outubro a março com média mensal de $186 \mathrm{~mm}$ e o de estiagem ocorre de abril a setembro com média mensal de $51 \mathrm{~mm}$. A precipitação média anual é de $1570 \mathrm{~mm}$ (DIAS et al., 2000) e a altitude varia de 60 a 1095 m (MONTES, 2005).

Situa-se na região norte da cidade de São Paulo, abrangendo também partes dos municípios de Mairiporã, Caieiras e Guarulhos. É constantemente visitado, principalmente o Núcleo Engordador, onde se localiza a Represa da Barragem e o Núcleo da Pedra Grande, de onde é possível ver toda a cidade de São Paulo e parte da Serra do Mar. É uma Unidade de Conservação de Proteção Integral paulista que abrange parte da Serra da Cantareira, tendo sido, como tal, tombada pela UNESCO em 1994. 
Desde a década de 1990 o Parque se encontra ameaçado pela especulação imobiliária, devido ao loteamento clandestino das áreas particulares contíguas, o que facilita a formação de favelas no entorno e mesmo dentro da área do Parque (DIAS et al., 2000).

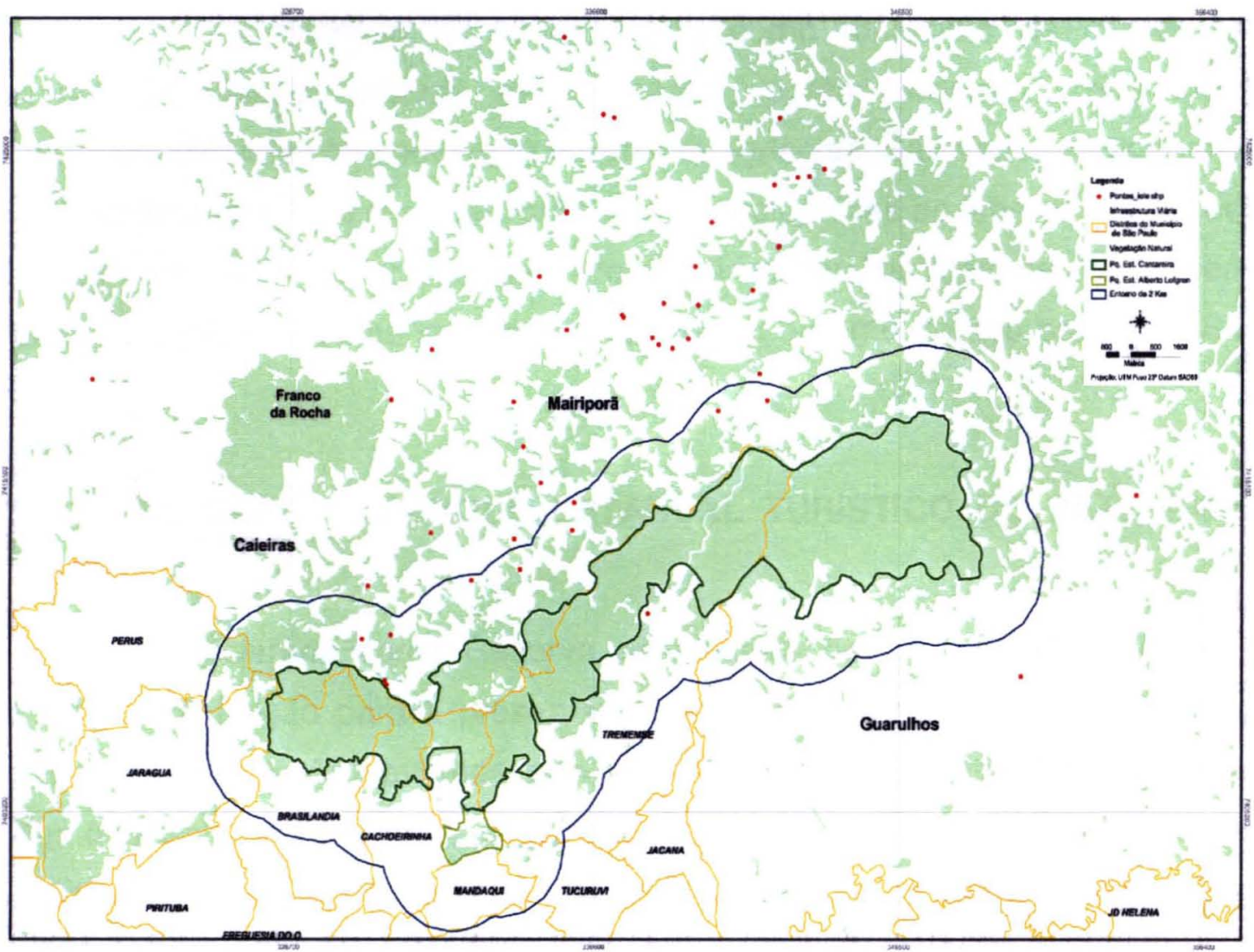

Fonte: Coordenadoria de Geoprocessamento e cartografia, Instituto Florestal, 2008.

Fig. 1. Parques Estaduais da Serra da Cantareira (PEC), Horto Florestal (PEAL) e entorno. Áreas de ocorrência de Leishmaniose Tegumentar Americana e vetores, 1997 a 2007. 


\subsubsection{ESTRADA DO ARLINDO, BAIRRO CAPUAVA - MUNICÍPIO DE COTIA}

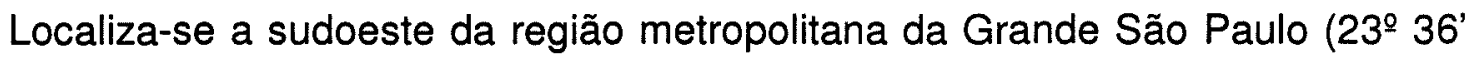
09" S e 46 55' 52" W, 820 m a.n.m), distando 34 km do marco zero da capital. Com relevo montanhoso e área de reserva florestal tombada pelo CONDEPHAAT. De sua área total, $325 \mathrm{~km}^{2}$ destinam-se à agricultura e pecuária e $182 \mathrm{~km}^{2}$ à ocupação urbana. Apresenta clima ameno, com temperaturas médias que variam entre $18^{\circ} \mathrm{C}$ e $25^{\circ} \mathrm{C}$ e relevo montanhoso. É caracterizado como município de grande porte. Apresenta população urbana predominante, porém existem conglomerados populacionais distantes da sede, com atividades agrícolas. São vários os condomínios de alto padrão com matas residuais próximas às residências ao lado de habitações de população com menor poder aquisitivo. Possui cinco favelas, além de conglomerados dispersos nos bairros, de habitações de população carente do tipo barracos (SILVA, 2006).

\subsubsection{BAIRRO SERRA - PARQUE ESTADUAL TURÍSTICO DO ALTO RIBEIRA (PETAR)}

Região declarada como Reserva da biosfera pela UNESCO, devido à sua importante contribuição para a preservação dos recursos naturais e da diversidade biológica do planeta. As cavernas são um dos principais atrativos procurados por aqueles que visitam o Parque e há aproximadamente 200 cavernas distribuídas em dois núcleos: Espírito Santo ou dos Caboclos e do Vale do Betary ou Santana, no qual se localiza a Caverna Santana, a de maior desenvolvimento planimétrico com 6.300 metros (KARMANN e FERRARI, 1999). O Bairro Serra localiza-se no Vale do Rio Betary e dista $5 \mathrm{Km}$ da Caverna Santana, na estrada que liga o município de Iporanga ao de Apiaí (Fig. 2). Neste bairro, localizam-se as pousadas, onde hospedam-se os visitantes do Núcleo Santana. 


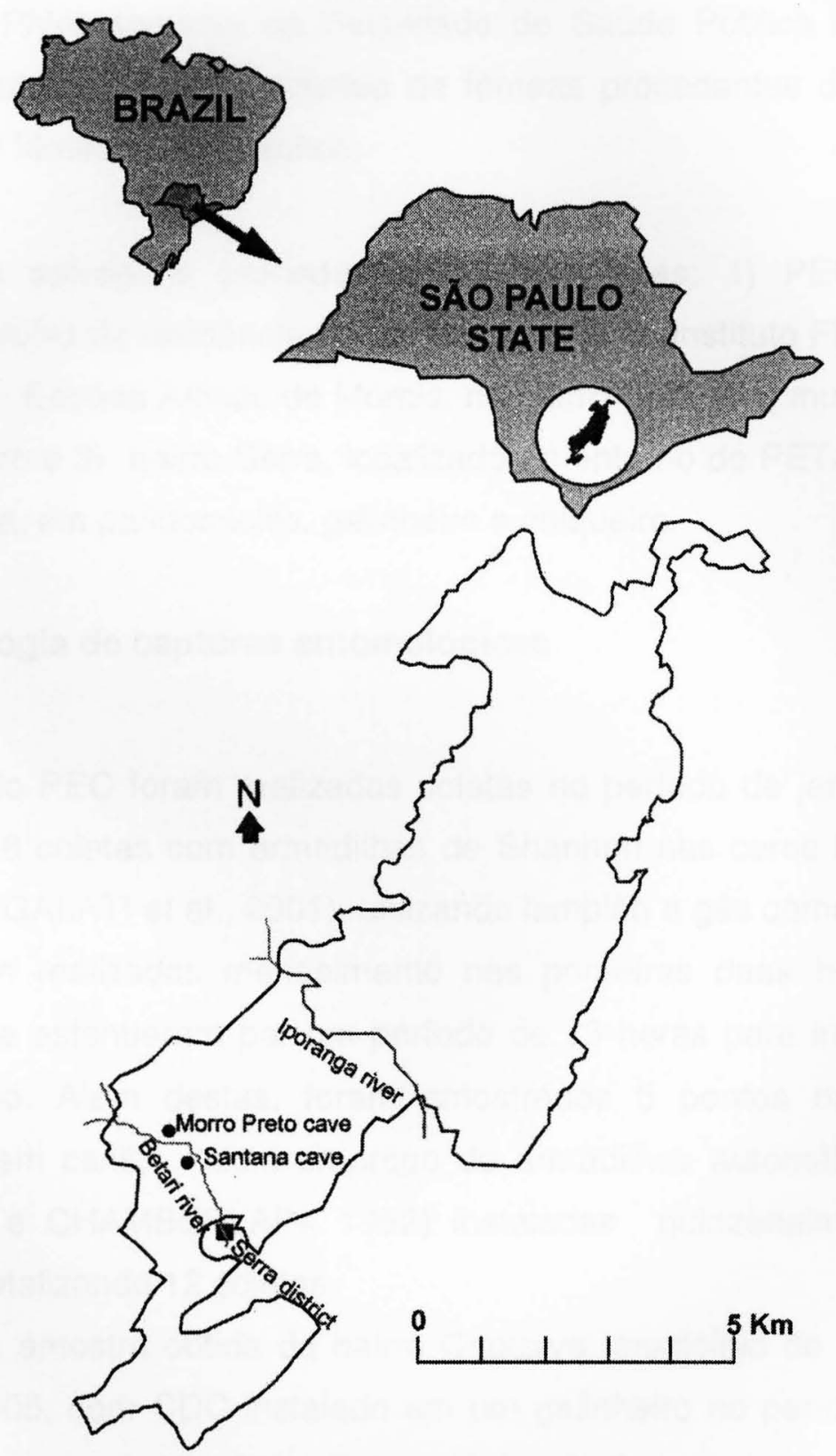

Fig. 2. Localização do Parque Estadual Turístico do Alto Ribeira (PETAR) no Estado de São Paulo e do Distrito Serra no município de Iporanga.

Fonte: GALATI et al. 2009 


\subsection{Procedência dos flebotomíneos submetidos ao teste}

Os flebotomíneos foram obtidos de duas fontes:

a) Colônia mantida no Laboratório de Entomologia em Saúde Pública/Phlebotominae da Faculdade de Saúde Pública da Universidade de São Paulo (FSP/USP), oriunda de fêmeas procedentes do Bairro Serra. Ao todo, 80 fêmeas e 80 machos.

b) Fêmeas selvagens procedentes de três áreas: 1) PEC, na mata e em peridomicílio da residência de um funcionário do Instituto Florestal, onde há um canil; 2) Estrada Arlindo de Morais, no bairro Capuava, município de Cotia, em galinheiro e 3) bairro Serra, localizado no entorno do PETAR, no município de Iporanga, em peridomicílio, galinheiro e chiqueiro.

\subsubsection{Metodologia de capturas entomológicas}

No PEC foram realizadas coletas no período de janeiro a setembro de 2009. Foram 6 coletas com armadilhas de Shannon nas cores branca (SHANNON, 1939) e preta (GALATI et al., 2001), utilizando lampião a gás como fonte luminosa. As capturas foram realizadas mensalmente nas primeiras duas horas do crepúsculo vespertino e se estenderam por um período de 13 horas para investigação do ritmo horário noturno. Além destas, foram amostrados 5 pontos na mata e um no peridomicílio, em canil, com emprego de armadilhas automáticas luminosas tipo CDC (SUDIA e CHAMBERLAIN, 1962) instaladas quinzenalmente das 18:00 às 06:00 horas, totalizando 12 coletas.

A amostra obtida do bairro Capuava, município de Cotia, foi capturada no ano de 2005, com CDC instalada em um galinheiro no peridomicílio. As coletas realizadas pelo setor de Vigilância Entomológica da Secretaria Municipal de Cotia.

No bairro Serra, foram feitas coletas por 3 dias consecutivos (29/06 a 01/07/09), com armadilha Shannon branca e preta instaladas no peridomicílio e com armadilhas automáticas tipo CDC no galinheiro. Além destas foram obtidos 
espécimes capturados em projeto desenvolvido nesta mesma localidade em 2002 e 2003, com as armadilhas tipo CDC instaladas no peridomicílio, galinheiro/chiqueiro (GALATI et al. 2009).

Nas capturas entomológicas foram preenchidas fichas contendo as seguintes informações: código da amostra, data das coletas, localização e características do habitat, tipo de armadilha empregada, horário das coletas e número de exemplares obtidos, espécies de flebotomíneos e estágios de Sella. As fêmeas utilizadas para a identificação do sangue ingerido tiveram a cabeça e a parte posterior do abdômen separadas, que após clarificadas conforme técnica descrita por FORATTINI (1973), foram identificadas segundo GALATI (2003). O resto do corpo foi utilizado para o teste ELISA.

\subsubsection{Número de espécimes submetido ao teste.}

PEC - 129 fêmeas de Pintomyia fischeri ingurgitadas ou não.

Bairro Capuava: 29 fêmeas, sendo 28 de Pi. fischeri e uma fêmea de Migonemyia migonei. Todas ingurgitadas.

Bairro Serra: procedentes da colônia: 80 fêmeas e 126 machos de $N y$. intermedia. Fêmeas selvagens: 52 de $\mathrm{Ny}$. intermedia capturadas em 2009 e 22 desta mesma espécie capturadas em 2002-2003 Portanto, 74 fêmeas foram testadas.

Portanto, no total das três áreas, somaram-se 232 fêmeas selvagens submetidas ao teste ELISA. Da colônia foram 80 fêmeas e 126 machos.

Todos os flebotomíneos coletados ficaram armazenados a $-20^{\circ} \mathrm{C}$. 


\subsection{Avaliação do hábito alimentar de flebotomíneos}

\subsubsection{Preparo das amostras}

O tórax e abdômen dos exemplares foram eluídos e macerados em $50 \mu \mathrm{l}$ de solução salina tamponada fosfatada, pH 7,2 (PBS - "Phosphate Buffered Saline"), dentro de microtubos de $1,5 \mathrm{ml}$, dotados de tampa, com o auxílio de pistilo de polipropileno acoplado a homogenizador automático (Sigma ${ }^{\mathrm{TM}}$ ). Após a trituração final, foram adicionados $350 \mu \mathrm{l}$ de PBS, perfazendo o volume final de aproximadamente $400 \mu \mathrm{l}$. O sobrenadante foi transferido para outro microtubo. As amostras foram mantidas a $-20{ }^{\circ} \mathrm{C}$ até serem testadas. A diluição estimada de sangue variou em função da avaliação visual do volume do mesmo nas fases de Sella que, segundo SERVICE et al. (1986) é de 0,01 a 0,3 mg entre os Psychodidae.

\subsubsection{Reação imunoenzimática (ELISA - Enzyme Linked-Immunosorbent Assay)}

A reação ELISA indireta constitui-se primeiramente na reação do antígeno, representado pelo anti-soro do hospedeiro-específico a ser pesquisado, com o sangue ingerido pelo flebótomo. Posteriormente, ocorre outra reação específica entre o complexo anti-soro+soro e o conjugado enzimático específico. Finalmente, ocorreu reação entre o conjugado e o substrato que possibilita a visualização da reação ocorrida por meio de coloração, sendo que a intensidade desta é proporcional à quantidade de sangue presente na amostra. A absorbância é lida por meio de leitor de placas de microtitulação contendo filtro com comprimento de onda adequado ao sistema.

Para verificar a sensibilidade da reação ELISA indireta para detectar volumes diferentes de sangue presente no abdômen de flebotomíneos, foram realizados experimentos empregando volumes distintos de sangue humano e de alguns animais alvo do estudo (Tabelas: 11 a 15). Assim sendo, para a identificação do sangue hospedeiro-específico ingerido por fêmeas ingurgitadas de flebotomíneos, utilizou-se a referida reação, cuja padronização foi realizada por meio de titulação em bloco para 
definição das concentrações ótimas de anti-soros e de conjugados peroxidase, específicos para humanos e alguns animais presentes nas áreas de estudo (Tabelas de 1 a 10).

A padronização do teste ELISA para identificar o sangue ingerido por flebotomíneos foi baseada na metodologia descrita por CHOW, WIRTZ e SCOTT (1993), com modificações, para a detecção dos anti-soros produzidos em cabra imunizados com sangue humano, de galinha, de rato, de cão e de suíno. Os antisoros e os conjugados peroxidase utilizados foram adquiridos comercialmente (Kirkegaard \& Perry Laboratories, Inc., Gaithersburg, Md. - KPL). Durante a padronização foram utilizadas placas de microtitulação, de vinil com fundo em $U$, flexíveis, com 96 poços da $\operatorname{COSTAR}^{\mathrm{TM} \otimes} 2797$.

A fim de estabelecer o limiar de reatividade do método, foi calculada a média aritmética das absorbâncias obtidas com 8 flebotomíneos sabidamente negativos (flebótomos machos alimentados com água açucarada), diariamente, conforme a equação: $C O=X+3 D P$, onde $X$ é a média aritmética de absorbâncias e DP é o desvio padrão obtido.

\subsubsection{Padronização dos anti-soros para identificação do sangue ingerido por dípteros da subfamília Phlebotominae}

As placas de microtitulação foram sensibilizadas por 1 hora à temperatura ambiente (TA) com $50 \mu \mathrm{l} /$ poço de anti-soro diluído em solução de PBS pH 7,2 e mantidas em câmara úmida, cuja concentração ideal determinada pela titulação em bloco foi testada às diluições de 1:500, 1:1000, 1:2000 e 1:4000 para humano, galinha e suíno. Para cão foram testadas as diluições de 1:500, 1:1000, 1:2000, 1:4000 e $1: 8000$ e para rato, de $1: 125,1: 250,1: 500$ e 1:1000. O anti-soro diluído foi retirado da placa e esta foi bloqueada com $200 \mu l /$ poço de solução de PBS pH 7,2, Tween 20 $0,05 \%$ e leite desnatado MOLICOTM $5 \%$ (PBS-T-L 5\%), permanecendo por 1 hora à TA em câmara úmida. As amostras testadas foram diluídas à 1:400. A solução de leite foi retirada da placa e foram adicionados $50 \mu \mathrm{l} /$ poço de sangue humano e dos animais testados nas diluições de 1:100, 1:200, 1:400 e 1:800 em PBS pH 7,2, acrescidos dos 
controles negativos (sangue heterólogo) com nova incubação por 2 horas à TA em câmara úmida. Após 3 lavagens com solução de PBS pH 7,2 contendo 0,05\% de Tween 20 (PBS-T), foi adicionado às placas $50 \mu /$ poço de conjugado peroxidase, diluído em PBS-T-L 2,5\% à 1:500, 1:1000, 1:2000, 1:4000 e 1:8000 para todas as amostras de sangue dos hospedeiros testados, com exceção do de rato, cujas diluições foram de 1:125, 1:250, 1:500 e 1:1000. As placas foram mantidas por 1 hora de incubação à TA em câmara úmida. Novo ciclo de lavagens com PBS-T foi efetuado, seguido de uma lavagem com água destilada, adicionando-se a seguir 100 $\mu \mathrm{l} /$ poço de $A B T S$ (solução $A+B$ ) v/v. Após 30 minutos à TA e em câmara úmida, os valores de absorbância foram obtidos após leitura das reações à $405 \mathrm{~nm}$ em leitor de microplacas (MULTISKAN EX - Primary EIA - V. 2.1-0®). Todos os testes foram feitos em duplicata.

\subsubsection{Sensibilidade da técnica ELISA para deteç̧ão de sangue ingerido por flebotomíneos empregando diferentes volumes}

As concentrações ótimas dos anti-soros e dos conjugados peroxidase foram determinadas utilizando diluições seriadas de antígenos, correspondendo à amplitude de sangue ingerido pelos flebotomíneos (variável de 0,01-3,0 mg). Assim, foram testadas diversas diluições dos sangues dos hospedeiros de modo a simular a quantidade de sangue ingerida por flebotomíneos, testando-se os seguintes volumes: 3ul, 2ul, 1ul, 0,5ul, 0,25ul, 0,125ul, 0,062ul e 0,031ul. Para os testes de especificidade, foram usados os sangues homólogos e heterólogos diluídos em PBS a $1: 400$.

4.3.2.3 Execução do ELISA com anti-soros humano, de galinha, de suíno, de rato e de cão para verificação do tempo de digestão do sangue nos flebotomíneos 
Com o intuito de avaliar o tempo de digestão e a capacidade de detecção do sangue ingerido, foi realizado teste com flebotomíneos criados em laboratório. Fêmeas de $\mathrm{Ny}$. intermedia foram alimentadas com sangue humano (bióloga lole Arumi Sei). Após o repasto sanguíneo, as fêmeas foram mortas por congelamento nos períodos de $0,2,4,6,8,10,12,24$ e 36 horas após a ingestão. À seguir, as amostras de fêmeas ingurgitadas foram submetidas ao teste ELISA indireto, conforme item 4.3.2.1, para a determinação da quantidade mínima de sangue digerido de diferentes hospedeiros, detectável pelo teste ELISA.

Não foi possível avaliar o tempo de digestão dos outros hospedeiros alvos de estudo, pois as fêmeas não se adaptaram aos métodos artificiais de alimentação, tais como, preservativo masculino sem lubrificante (membrana de látex), absorvente interno (TAMPAX®), conforme foi utilizado por VICENTIN (2006) e LAPORTA (2007).

Posteriormente, o método de ELISA foi desenvolvido com amostras de flebotomíneos capturados nos pontos de coleta descritos no item 4.2.1. 


\subsection{Análises Estatísticas}

Nos resultados obtidos neste trabalho foram determinadas as médias, desvios padrão dos limiares de reatividade (ponto de corte) e o coeficiente de correlação de Pearson (programa SPSS for Windows, Release 5.02) para verificar a possivel correlação entre as absorbâncias obtidas e o volume de sangue presente nas amostras testadas. Os valores das absorbâncias obtidas no teste ELISA com fêmeas ingurgitadas, segundo o tipo de fonte alimentar, foram expressos em percentuais em relação ao total de testes positivos. 


\section{RESULTADOS}

\subsection{Padronização da reação de ELISA para detecção de repasto sanguíneo}

\subsubsection{Determinação das diluições ideais dos sangues, anti-soros e conjugados.}

Na padronização da técnica de ELISA para identificação de repasto alimentar foram testados sangues humano, de galinha, de suíno, de cão e de rato, com seus correspondentes anti-soros e conjugados, além dos controles negativos (sangue heterólogo). Os resultados da titulação em bloco para determinação das diluições ótimas dos sangues, anti-soros e conjugados considerados, podem ser vistos nas Tabelas 1, 2, 3, 4, 5, 6, 7, 8, 9 e 10.

Em relação ao anti-soro humano e conjugado anti-humano, a diluição mais adequada foi de $1 / 4.000$ para ambos reagentes (Tabela 1) e diluição do sangue humano escolhida foi $1 / 400$ (Tabela 2).

Tabela 1 - Padronização da reação de ELISA para anti-soro de captura humano e conjugado peroxidase anti-humano, com sangue humano (controle positivo) e de galinha (heterólogo ou controle negativo).

\begin{tabular}{lccccccccc}
\hline \multicolumn{7}{c}{ Anti-soro - humano } \\
\hline \multicolumn{7}{c}{ Sangue humano } & & \multicolumn{5}{c}{ Sangue de galinha } \\
\hline Conjugado & $1 / 500$ & $1 / 1.000$ & $1 / 2.000$ & $1 / 4.000$ & $1 / 500$ & $1 / 1.000$ & $1 / 2.000$ & $1 / 4.000$ \\
$1 / 500$ & $>2.000$ & $>2.000$ & $>2.000$ & $>2.000$ & 0.040 & 0.042 & 0.034 & 0.038 \\
$1 / 1.000$ & $>2.000$ & $>2.000$ & $>2.000$ & $>2.000$ & 0.033 & 0.034 & 0.034 & 0.034 \\
$1 / 2.000$ & $>2.000$ & $>2.000$ & $>2.000$ & $>2.000$ & 0.038 & 0.037 & 0.035 & 0.036 \\
$1 / 4.000$ & 1.934 & 1.978 & 1.871 & 1.735 & 0.032 & 0.033 & 0.036 & 0.041 \\
$1 / 8.000$ & 1.376 & 1.288 & 1.179 & 0.893 & 0.038 & 0.023 & 0.011 & 0.014 \\
\hline
\end{tabular}

Resultados expressos em Absorbância: $405 \mathrm{~nm}$ Média do "Blank" = 0.068 
Tabela 2 - Determinação da diluição ideal do sangue humano frente à diluição do anti-soro de captura humano (1/4.000) e conjugado peroxidase anti-humano (1/4.000). Controle negativo: sangue de galinha (heterólogo).

\begin{tabular}{lcccc|cccc}
\hline \multicolumn{8}{c}{ Anti-soro - humano (1/4.000) } \\
\hline Sangue humano & \multicolumn{5}{c}{ Sangue de galinha } \\
\hline Conjugado & $\mathbf{1 / 1 0 0}$ & $\mathbf{1 / 2 0 0}$ & $\mathbf{1 / 4 0 0}$ & $\mathbf{1 / 8 0 0}$ & $\mathbf{1 / 1 0 0}$ & $\mathbf{1 / 2 0 0}$ & $\mathbf{1 / 4 0 0}$ & $\mathbf{1 8 0 0}$ \\
$\mathbf{1 / 4 0 0 0}$ & $>2.000$ & 1.947 & 1.856 & 0.584 & 0.040 & 0.042 & 0.034 & 0.038 \\
\hline
\end{tabular}

Resultados expressos em Absorbância: $405 \mathrm{~nm}$

Média do "Blank" $=0.057$

Em relação ao anti-soro de galinha e conjugado anti-galinha, as diluições mais adequadas foram respectivamente de 1/4000 e 1/8000 (Tabela 3) e diluição do sangue de galinha escolhida foi de 1/400 (Tabela 4).

Tabela 3 - Padronização da reação de ELISA para anti-soro de captura de galinha e conjugado peroxidase anti-galinha, com sangue de galinha (controle positivo) e sangue humano (heterólogo ou controle negativo).

\begin{tabular}{lcccc|cccc}
\hline \multicolumn{7}{c}{ Anti-soro - galinha } \\
\hline Conjugado & $\mathbf{1 / 5 0 0}$ & $\mathbf{1 / 1 . 0 0 0}$ & $\mathbf{1 / 2 . 0 0 0}$ & $\mathbf{1 / 4 . 0 0 0}$ & $\mathbf{1 / 5 0 0}$ & $\mathbf{1 / 1 . 0 0 0}$ & $\mathbf{1 / 2 . 0 0 0}$ & $\mathbf{1 / 4 . 0 0 0}$ \\
$\mathbf{1 / 5 0 0}$ & $>2.000$ & $>2.000$ & $>2.000$ & $>2.000$ & 0.080 & 0.033 & 0.036 & 0.036 \\
$\mathbf{1 / 1 . 0 0 0}$ & $>2.000$ & $>2.000$ & $>2.000$ & $>2.000$ & 0.043 & 0.030 & 0.033 & 0.033 \\
$\mathbf{1 / 2 . 0 0 0}$ & $>2.000$ & 1.994 & 1.897 & 1.764 & 0.035 & 0.034 & 0.034 & 0.035 \\
$\mathbf{1 / 4 . 0 0 0}$ & 1.934 & 1.845 & 1.723 & 1.699 & 0.036 & 0.032 & 0.031 & 0.035 \\
$\mathbf{1 / 8 . 0 0 0}$ & 1.459 & 1.329 & 1.425 & $\mathbf{1 . 2 1 9}$ & 0.024 & 0.017 & 0.025 & 0.021 \\
\hline
\end{tabular}

Resultados expressos em Absorbância: $405 \mathrm{~nm}$

Média do "Blank" = 0.084 
Tabela 4 - Determinação da diluição ideal do sangue de galinha frente à diluição do anti-soro de captura de galinha (1/4.000) e conjugado peroxidase anti-galinha (1/8.000). Controle negativo: sangue humano (heterólogo)

\begin{tabular}{lcccccccc}
\hline \multicolumn{8}{c}{ Anti-soro - galinha (1/4.000) } \\
\hline \multicolumn{8}{c}{ Sangue galinha } & \multicolumn{5}{c}{ Sangue humano } \\
\hline Conjugado & $1 / 100$ & $1 / 200$ & $1 / 400$ & $1 / 800$ & $1 / 100$ & $1 / 200$ & $1 / 400$ & $1 / 800$ \\
$1 / 8.000$ & $>2.000$ & 1.798 & 1.289 & 0.501 & 0.033 & 0.024 & 0.021 & 0.029 \\
\hline
\end{tabular}

Resultados expressos em Absorbância: $405 \mathrm{~nm}$

Média do "Blank" = 0.072

Em relação ao anti-soro de suíno e conjugado Anti-suíno, as diluições mais adequadas foram respectivamente de 1/2000 e 1/8000 (Tabela 5) e diluição do sangue de suíno escolhida foi de 1/400 (Tabela 6).

Tabela 5 - Padronização da reação de ELISA para anti-soro de captura de suíno e conjugado peroxidase Anti-suíno, com sangue de suíno (controle positivo) e sangue humano (heterólogo ou controle negativo).

\begin{tabular}{lcccc|cccc}
\hline \multicolumn{7}{c}{ Anti-soro-suíno } \\
\hline \multicolumn{1}{c}{ Sangue suíno } & & \multicolumn{5}{c}{ Sangue humano } \\
\hline Conjugado & $\mathbf{1 / 5 0 0}$ & $\mathbf{1 / 1 . 0 0 0}$ & $\mathbf{1 / 2 . 0 0 0}$ & $\mathbf{1 / 4 . 0 0 0}$ & $\mathbf{1 / 5 0 0}$ & $\mathbf{1 / 1 . 0 0 0}$ & $\mathbf{1 / 2 . 0 0 0}$ & $\mathbf{1 / 4 . 0 0 0}$ \\
$\mathbf{1 / 5 0 0}$ & $>2.000$ & $>2.000$ & $>2.000$ & $>2.000$ & 0.067 & 0.045 & 0.057 & 0.076 \\
$\mathbf{1 / 1 . 0 0 0}$ & $>2.000$ & $>2.000$ & $>2.000$ & $>2.000$ & 0.068 & 0.034 & 0.023 & 0.035 \\
$\mathbf{1 / 2 . 0 0 0}$ & $>2.000$ & $>2.000$ & 1.967 & 1.876 & 0.047 & 0.048 & 0.028 & 0.025 \\
$\mathbf{1 / 4 . 0 0 0}$ & 1.934 & 1.935 & 1.821 & 1.609 & 0.039 & 0.027 & 0.033 & 0.028 \\
$\mathbf{1 / 8 . 0 0 0}$ & 1.579 & 1.378 & $\mathbf{1 . 2 8 9}$ & 0.678 & 0.014 & 0.029 & 0.018 & 0.015 \\
\hline
\end{tabular}

Resultados expressos em Absorbância: $405 \mathrm{~nm}$

Média do "Blank" $=.0 .058$ 
Tabela 6 - Determinação da diluição ideal do sangue de suíno frente à diluição do anti-soro de captura de suíno (1/2.000) e conjugado peroxidase Anti-suíno (1/8.000). Controle negativo: sangue humano (heterólogo)

\begin{tabular}{lrrrrrrrr}
\hline \multicolumn{8}{c}{ Anti-soro - suíno (1/2.000) } \\
\hline Sangue suíno & \multicolumn{5}{c}{ Sangue humano } \\
\hline Conjugado & $1 / 100$ & $1 / 200$ & $1 / 400$ & $1 / 800$ & $1 / 100$ & $1 / 200$ & $1 / 400$ & $1 / 800$ \\
$1 / 8.000$ & $>2.000$ & 1.984 & 1.312 & 0.523 & 0.067 & 0.072 & 0.035 & 0.031 \\
\hline
\end{tabular}

Resultados expressos em Absorbância: $405 \mathrm{~nm}$

Média do "Blank" $=.0 .082$

Em relação ao anti-soro de cão e conjugado anti-cão, as diluições mais adequadas foram respectivamente de $1 / 8000$ e 1/2000 (Tabela 7) e diluição do sangue de cão escolhida foi de 1/400 (Tabela 8).

Tabela 7 - Padronização da reação de ELISA para anti-soro de captura de cão e conjugado peroxidase anti-cão, com sangue de cão (controle positivo) e sangue galinha (heterólogo ou controle negativo).

\begin{tabular}{lccccc|ccccc}
\hline \multicolumn{10}{c}{ Anti-soro-cão } \\
\hline \multicolumn{10}{c}{ Sangue cão } & \multicolumn{7}{c}{ Sangue galinha } \\
\hline Conjugado & $\mathbf{1 / 5 0 0}$ & $\mathbf{1 / 1 . 0 0 0}$ & $\mathbf{1 / 2 . 0 0 0}$ & $\mathbf{1 / 4 . 0 0 0}$ & $\mathbf{1 / 8 . 0 0 0}$ & $\mathbf{1 / 5 0 0}$ & $\mathbf{1 / 1 . 0 0 0}$ & $\mathbf{1 / 2 . 0 0 0}$ & $\mathbf{1 / 4 . 0 0 0}$ & $\mathbf{1 / 8 . 0 0 0}$ \\
$\mathbf{1 / 5 0 0}$ & $>2.000$ & $>2.000$ & $>2.000$ & $>2.000$ & $>2.000$ & 0.061 & 0.055 & 0.073 & 0.046 & 0.054 \\
$\mathbf{1 / 1 . 0 0 0}$ & $>2.000$ & $>2.000$ & $>2.000$ & 1.822 & 1950 & 0.058 & 0.039 & 0.021 & 0.032 & 0.032 \\
$\mathbf{1 / 2 . 0 0 0}$ & $>2.000$ & 1.929 & 1.832 & 1.616 & $\mathbf{1 . 4 7 7}$ & 0.037 & 0.028 & 0.034 & 0.024 & 0.022 \\
$\mathbf{1 / 4 . 0 0 0}$ & 1.934 & 1.935 & 1.821 & 0.856 & 0.609 & 0.035 & 0.023 & 0.030 & 0.027 & 0.019 \\
$\mathbf{1 / 8 . 0 0 0}$ & 1.579 & 1.378 & 1.289 & 0.622 & 0.473 & 0.014 & 0.019 & 0.018 & 0.013 & 0.016 \\
\hline
\end{tabular}

Resultados expressos em Absorbância: $405 \mathrm{~nm}$

Média do "Blank" =.0.065 
Tabela 8 - Determinação da diluição ideal do sangue de cão frente à diluição do anti-soro de captura de cão (1/8.000) e conjugado peroxidase anti-cão (1/2.000). Controle negativo: sangue de galinha (heterólogo).

\begin{tabular}{lcccc|cccc}
\hline \multicolumn{8}{c}{ Anti-soro - Cão (1/8.000) } \\
\hline \multicolumn{1}{c}{ Sangue cão } & \multicolumn{4}{c}{ Sangue galinha } \\
\hline Conjugado & $\mathbf{1 / 1 0 0}$ & $\mathbf{1 / 2 0 0}$ & $\mathbf{1 / 4 0 0}$ & $\mathbf{1 / 8 0 0}$ & $\mathbf{1 / 1 0 0}$ & $\mathbf{1 / 2 0 0}$ & $\mathbf{1 / 4 0 0}$ & $\mathbf{1 / 8 0 0}$ \\
$\mathbf{1 / 2 . 0 0 0}$ & $>2.000$ & 1.977 & $\mathbf{1 . 2 9 0}$ & 0.498 & 0.061 & 0.052 & 0.034 & 0.028 \\
\hline
\end{tabular}

Resultados expressos em Absorbância: $405 \mathrm{~nm}$

Média do "Blank" $=0.073$

Em relação ao anti-soro de rato e conjugado anti-rato, optamos por diluição diferenciada devido ao menor rendimento apresentado pelos mesmos, a diluição mais adequada foi de 1/500 para ambos reagentes (Tabela 9) e diluição do sangue de rato escolhida foi de $1 / 400$ (Tabela 10).

Tabela 9 - Padronização da reação de ELISA para anti-soro de captura de rato e conjugado peroxidase anti-rato, com sangue de rato (controle positivo) e sangue galinha (heterólogo ou controle negativo).

\begin{tabular}{lcccc|cccc}
\hline \multicolumn{7}{c}{ Anti-soro-rato } \\
\hline \multicolumn{7}{c}{ Sangue rato } & & \multicolumn{4}{c}{ Sangue galinha } \\
\hline $\mathbf{1 / 1 2 5}$ & $\mathbf{1 / 1 2 5}$ & $\mathbf{1 / 2 5 0}$ & $\mathbf{1 / 5 0 0}$ & $\mathbf{1 / 1 . 0 0 0}$ & $\mathbf{1 / 1 2 5}$ & $\mathbf{1 / 2 5 0}$ & $\mathbf{1 / 5 0 0}$ & $\mathbf{1 / 1 . 0 0 0}$ \\
$\mathbf{1 / 2 5 0}$ & 1.901 & 1.917 & 1.811 & 1.402 & 0.057 & 0.048 & 0.063 & 0.078 \\
$\mathbf{1 / 5 0 0}$ & 1.820 & 1.688 & $\mathbf{1 . 3 6 7}$ & 0.667 & 0.077 & 0.054 & 0.048 & 0.039 \\
$\mathbf{1 / 1 . 0 0 0}$ & 1.634 & 1.935 & 0.866 & 0.429 & 0.031 & 0.023 & 0.031 & 0.029 \\
\hline
\end{tabular}

Resultados expressos em Absorbância: $405 \mathrm{~nm}$

Média do "Blank" $=0.067$ 
Tabela 10 - Determinação da diluição ideal do sangue de rato frente à diluição do anti-soro de captura de rato (1/500) e conjugado peroxidase anti-rato $(1 / 500)$. Controle negativo: sangue de galinha (heterólogo)

\begin{tabular}{lcccc|cccc}
\hline \multicolumn{8}{c}{ Anti-soro - rato (1/500) } \\
\hline \multicolumn{8}{c}{ Sangue rato } & \multicolumn{4}{c}{ Sangue galinha } \\
\hline Conjugado & $\mathbf{1 / 1 0 0}$ & $\mathbf{1 / 2 0 0}$ & $\mathbf{1 / 4 0 0}$ & $\mathbf{1 / 8 0 0}$ & $\mathbf{1 / 1 0 0}$ & $\mathbf{1 / 2 0 0}$ & $\mathbf{1 / 4 0 0}$ & $\mathbf{1 / 8 0 0}$ \\
$\mathbf{1 / 5 0 0}$ & $>2.000$ & 1.987 & 1.390 & 0.549 & 0.072 & 0.045 & 0.033 & 0.021 \\
\hline
\end{tabular}

Resultados expressos em Absorbância: $405 \mathrm{~nm}$

Média do "Blank" = 0.076 


\subsubsection{Sensibilidade da técnica para detecção de sangue empregando diferentes} volumes de sangue.

A sensibilidade da técnica ELISA foi verificada através da utilização de sangue humano, de galhinha, de suíno, de cão e de rato em diferentes volumes. Os resultados estão demonstrados nas Tabelas 11, 12,13,14 e 15, respectivamente.

Houve uma correlação negativa pelo teste de Pearson $(r=-0,1623 ; P=$ $0.701 ; n=8$ ) entre os valores das absorbâncias e o volume de sangue humano, contudo sem significância estatística. Todavia, a positividade se manteve até a última diluição. Os machos não apresentaram reatividade em nenhuma diluição testada (Tabela 11).

Tabela 11 - Determinação da sensibilidade do teste ELISA quanto a deteç̧ão de diferentes volumes de sangue humano frente à diluição do anti-soro de captura humano (1/4.000) e conjugado peroxidase anti-humano (1/4.000). Controle negativo: machos.

\begin{tabular}{lcccccccc}
\hline & \multicolumn{8}{c}{ Anti-soro- humano (1/4.000) e Conjugado (1/4000) } \\
Sangue $(\mu \mathrm{l})$ & $\mathbf{3}$ & $\mathbf{2}$ & $\mathbf{1}$ & $\mathbf{0 , 5 0}$ & $\mathbf{0 , 2 5}$ & $\mathbf{0 , 1 2 5}$ & $\mathbf{0 , 0 6 2}$ & $\mathbf{0 , 0 3 1}$ \\
\hline humano & $\mathbf{1 . 1 2 3}$ & 0.935 & 1.177 & 1.112 & 1.288 & 1.013 & 1.135 & 0.970 \\
Machos $^{*}$ & 0.027 & 0.029 & 0.029 & 0.028 & 0.027 & 0.027 & 0.026 & 0.026 \\
\hline
\end{tabular}

Resultados expressos em Absorbância: $405 \mathrm{~nm}$

Machos: espécimes de flebotomineos ( $\mathrm{Ny}$. intermedia) triturados em PBS pH 7.2.

Média do "Blank" $=.0 .082$ 
Houve uma correlação negativa entre os valores das absorbâncias e 0 volume de sangue de galinha pelo teste de Pearson $(r=-0,3223 P=0.436 ; n=$ 8), porém sem significância estatística. No entanto, a positividade se manteve até a última diluição. Os machos não apresentaram reatividade em nenhuma diluição testada (Tabela 12).

Tabela 12 - Determinação da sensibilidade do teste ELISA quanto a deteç̧ão de diferentes volumes de sangue de galinha frente à diluição do anti-soro de captura de galinha (1/4.000) e conjugado peroxidase anti-galinha (1/8.000). Controle negativo: machos.

\begin{tabular}{lcccccccc}
\hline & \multicolumn{1}{c}{ Anti-soro - galinha $(1 / 4.000)$} & e Conjugado $(1 / 8.000)$ \\
Sangue $(\boldsymbol{\mu l})$ & $\mathbf{3}$ & $\mathbf{2}$ & $\mathbf{1}$ & $\mathbf{0 , 5 0}$ & $\mathbf{0 , 2 5}$ & $\mathbf{0 , 1 2 5}$ & $\mathbf{0 , 0 6 2}$ & $\mathbf{0 , 0 3 1}$ \\
\hline Galinha & 0.770 & 0.615 & 0.831 & 0.908 & 0.732 & 0.819 & 0.783 & 0.717 \\
Machos & 0.033 & 0.033 & 0.034 & 0.032 & 0.035 & 0.031 & 0.033 & 0.053 \\
\hline
\end{tabular}

Resultados expressos em Absorbância: $405 \mathrm{~nm}$

Machos: espécimes de flebotomíneos ( $N y$. intermedia) triturados em PBS pH 7.2.

Média do "Blank" = 0.072

Foi observado declínio dos valores das absorbâncias conforme a diminuição do volume de sangue de suíno, com a correlação sendo positiva pelo teste de Pearson ( $r=0.8141 ; P=0.014 ; n=8$ ) e significativa. Os machos não apresentaram reatividade em nenhuma diluição testada (Tabela 13). 
Tabela 13 - Determinação da sensibilidade do teste ELISA quanto a detecção de diferentes volumes de sangue de suíno frente à diluição do anti-soro de captura de suíno (1/2.000) e conjugado peroxidase Anti-suíno (1/8.000). Controle negativo: machos.

\begin{tabular}{lcccccccc}
\hline \multicolumn{10}{c}{ Anti-soro - suíno (1/2.000) e Conjugado (1/8.000) } \\
Sangue ( $\mu \mathrm{l})$ & $\mathbf{3}$ & $\mathbf{2}$ & $\mathbf{1}$ & $\mathbf{0 , 5 0}$ & $\mathbf{0 , 2 5}$ & $\mathbf{0 , 1 2 5}$ & $\mathbf{0 , 0 6 2}$ & $\mathbf{0 , 0 3 1}$ \\
\hline Suíno & 0.698 & 0.722 & 0.600 & 0.465 & 0.388 & $\mathbf{0 . 2 6 5}$ & 0.140 & 0.068 \\
machos & 0.054 & 0.055 & 0.039 & 0.026 & 0.028 & 0.027 & 0.027 & 0.021 \\
\hline
\end{tabular}

Resultados expressos em Absorbância: $405 \mathrm{~nm}$.

Machos: espécimes de flebotomineos ( $N y$. intermedia) triturados em PBS pH 7.2.

Média do "Blank" $=0.058$

Foi observado declínio dos valores das absorbâncias conforme a diminuição do volume de sangue de cão. Os machos não apresentaram reatividade em nenhuma diluição testada (Tabela 14). A correlação de Pearson foi positiva ( $r=0.8696 ; P=$ $0.05 ; n=8)$ e significativa

Tabela 14 - Determinação da sensibilidade do teste ELISA quanto a deteç̧ão de diferentes volumes de sangue de cão frente à diluição do anti-soro de captura de cão (1/8.000) e conjugado peroxidase anti-cão (1/2.000). Controle negativo: machos.

\begin{tabular}{lcccccccc}
\hline & \multicolumn{1}{c}{ Anti-soro - cão (1/8.000) e Conjugado (1/2000) } \\
Sangue $(\boldsymbol{\mu l})$ & $\mathbf{3}$ & $\mathbf{2}$ & $\mathbf{1}$ & $\mathbf{0 , 5 0}$ & $\mathbf{0 , 2 5}$ & $\mathbf{0 , 1 2 5}$ & $\mathbf{0 , 0 6 2}$ & $\mathbf{0 , 0 3 1}$ \\
\hline Cão & 0.810 & 0.536 & 0.632 & 0.555 & 0.317 & $\mathbf{0 . 2 8 9}$ & 0.256 & 0.230 \\
machos & 0.042 & 0.036 & 0.041 & 0.035 & 0.036 & 0.027 & 0.029 & 0.023 \\
\hline
\end{tabular}

Resultados expressos em Absorbância: $405 \mathrm{~nm}$.

Machos: espécimes de flebotomíneos ( $N y$. intermedia) triturados em PBS pH 7.2.

Média do "Blank" = 0.063 
Foi observado declínio dos valores das absorbâncias conforme a diminuição do volume de sangue de rato, com maior queda nas últimas duas diluições testadas. No teste de Pearson a correlação foi positiva e significativa entre as duas variáveis $(r=0.8065 ; P=0.016 ; n=8)$. Os machos não apresentaram reatividade em nenhuma diluição testada (Tabela 15).

Tabela 15 - Determinação da sensibilidade do teste ELISA quanto a deteç̧ão de diferentes volumes de sangue de rato frente à diluição do anti-soro de captura de rato $(1 / 500)$ e conjugado peroxidase anti-rato (1/500). Controle negativo: machos.

\begin{tabular}{lcccccccc}
\hline \multicolumn{10}{c}{ Anti-soro - rato (1/500) e Conjugado (1/500) } \\
Sangue $(\boldsymbol{\mu l})$ & $\mathbf{3}$ & $\mathbf{2}$ & $\mathbf{1}$ & $\mathbf{0 , 5 0}$ & $\mathbf{0 , 2 5}$ & $\mathbf{0 , 1 2 5}$ & $\mathbf{0 , 0 6 2}$ & $\mathbf{0 , 0 3 1}$ \\
\hline Rato & $\mathbf{0 . 5 1 3}$ & 0.420 & 0.338 & 0.314 & $\mathbf{0 . 3 3 7}$ & 0.219 & 0.122 & 0.076 \\
Machos & 0.034 & 0.025 & 0.037 & 0.029 & 0.019 & 0.027 & 0.016 & 0.021 \\
\hline
\end{tabular}

Resultados expressos em Absorbância: $405 \mathrm{~nm}$

Machos: espécimes de flebotomineos (Ny. intermedia) triturados em PBS pH 7.2.

Média do "Blank" $=0,062$

\subsubsection{Avaliação do tempo de digestão e capacidade de detecção de positividade para sangue humano ingerido pelos flebotomíneos.}

Com o intuito de avaliar o tempo de digestão e a capacidade de deteç̧ão do sangue ingerido foi realizado teste com flebotomíneos criados em laboratório e alimentados com sangue humano e sacrificados nos períodos de $0,2,4,6,8,10$, 12, 24 e 36 horas (Tabela 16).

Foi observado declínio das absorbâncias nas fêmeas ingurgitadas testadas conforme o maior tempo de digestão do sangue humano; os machos não apresentaram reatividade (Tabela 16), com 0 teste de Pearson, para $n=9$, mostrando correlação negativa e significante para o sangue humano $(r=-0.772$; $P=0.014)$. 
Tabela 16 - Verificação do tempo de digestão do sangue ingerido pelos flebotomíneos (fêmeas ingurgitadas com sangue: humano) em diferentes períodos de tempo frente à diluição do anti-soro de captura de humano (1/4.000) e conjugado peroxidase anti-humano (1/4.000). Controle negativo: machos.

\begin{tabular}{lcccccccccc}
\hline \multicolumn{10}{c}{ Tempo de digestão- horas } \\
\hline Anti-soro- humano & $(1 / 4.000)$, Conjugado $(1 / 4.000)$ & e sangue $(1 / 400)$ \\
\hline Horas & $\mathbf{0}$ & $\mathbf{2}$ & $\mathbf{4}$ & $\mathbf{6}$ & $\mathbf{8}$ & $\mathbf{1 0}$ & $\mathbf{1 2}$ & $\mathbf{2 4}$ & $\mathbf{3 6}$ \\
\hline Fêmeas & 0.848 & 0.554 & 0.670 & 0.437 & 0.408 & 0.320 & 0.148 & 0.229 & $\mathbf{0 . 1 3 9}$ \\
Machos & 0.095 & 0.062 & 0.058 & 0.065 & 0.061 & 0.064 & 0.062 & 0.065 & 0.058 \\
\hline
\end{tabular}

Resultados expressos em Absorbância: $405 \mathrm{~nm}$

Média do "Blank" $=0.060$

\subsubsection{Limiares de reatividade (ponto de corte)}

Para uma melhor especificidade dos resultados das reações de ELISA com os anti-soros e conjugados considerados nos testes, os limiares de reatividade para cada um deles (humano, galinha, suíno, cão e rato) foram determinados acrescentando às médias aritméticas das absorbâncias obtidas com flebotomíneos machos (controles negativos), 3 desvios padrão, conforme resultados demonstrados na Tabela 17. 
Tabela 17 - Determinação dos limiares de reatividade (ponto de corte) da reação de ELISA com os 5 anti-soros e conjugados (humano, galinha, suíno, cão e rato). Flebotomíneos machos $(\mathrm{N}=8)$. Diluições dos anti-soros e conjugados conforme definido na padronização. Resultados expressos em absorbâncias a $405 \mathrm{~nm}$.

\begin{tabular}{lccc}
\hline $\begin{array}{l}\text { Anti- } \\
\text { soros/conjugados }\end{array}$ & $\begin{array}{c}\text { Média } \\
\text { (Abs) }\end{array}$ & D.P. & $\begin{array}{c}\text { Ponto de corte } \\
\text { M+3DP }\end{array}$ \\
\hline Humano & 0.034 & 0.022 & $\mathbf{0 . 1 0 0}$ \\
Galinha & $(0.011-0.079)$ & & \\
& 0.046 & 0.028 & $\mathbf{0 . 1 3 0}$ \\
Suíno & $(0.0015-0.122)$ & & \\
& 0.053 & 0.033 & $\mathbf{0 . 1 5 2}$ \\
Cão & $(0.012-0.144)$ & & \\
& 0.120 & 0.054 & $\mathbf{0 . 2 8 2}$ \\
Rato & $(0.030-0.260)$ & & \\
& 0.115 & 0.056 & $\mathbf{0 . 2 8 3}$ \\
\hline
\end{tabular}

$\mathrm{M}=$ média das Absorbâncias (DO) ; $\mathrm{DP}=$ Desvio Padrão

(Abs) - Absorbâncias mínimas e máximas dos soros negativos

5.3 Reação de ELISA para deteç̧ão de repasto alimentar em espécimes flebotomíneos capturados em campo

O número de fêmeas testadas e as reagentes, segundo localidade e espécie constam da Tabela 18. Foram testados 232 espécimes de fêmeas de flebotomíneos capturadas em três localidades: PEC, PETAR e Cotia, destes 54 foram positivas no teste $(23,3 \%)$ e 178 espécimes foram negativos (76,7\%) Das 129 fêmeas de Pi. fischeri oriundas do PEC testadas, 14 (10,85\%) foram reagentes. Do bairro Serra, município de lporanga, das 74 amostras de $\mathrm{Ny}$. intermedia testadas, $12(16,2 \%)$ foram 
reagentes. De Cotia, bairro Capuava, das 29 amostras testadas (28 de Pi. fischeri e 1 de $\mathrm{Mg}$. migonel) 28 foram reagentes $(96,6 \%)$ para algum tipo dos sangues testados.

Tabela 18. Número de fêmeas submetidas ao teste ELISA e freqüência de reatividade a algum tipo de sangue, segundo espécie e local de captura.

\begin{tabular}{|c|c|c|c|c|c|c|c|c|c|c|c|c|}
\hline \multirow{3}{*}{$\begin{array}{l}\text { Local de } \\
\text { captura } \\
\text { Espécie }\end{array}$} & \multicolumn{3}{|c|}{ PEC } & \multicolumn{3}{|c|}{ Bairro Capuava } & \multicolumn{3}{|c|}{ Bairro Serra } & \multicolumn{3}{|c|}{ Total } \\
\hline & \multirow{2}{*}{$\begin{array}{c}\text { Test. } \\
\mathrm{N}\end{array}$} & \multicolumn{2}{|c|}{ Reag. } & \multirow{2}{*}{$\begin{array}{c}\text { Test. } \\
\mathrm{N}\end{array}$} & \multicolumn{2}{|c|}{ Reag. } & \multirow{2}{*}{$\begin{array}{c}\text { Test. } \\
\mathrm{N}\end{array}$} & \multicolumn{2}{|c|}{ Reag. } & \multirow{2}{*}{$\begin{array}{c}\text { Test. } \\
\mathrm{N}\end{array}$} & \multicolumn{2}{|c|}{ Reag. } \\
\hline & & $N$ & $\%$ & & $N$ & $\%$ & & $\mathrm{~N}$ & $\%$ & & $N$ & $\%$ \\
\hline Pi. fischeri & 129 & 14 & 10,85 & 28 & 27 & 96,4 & - & - & - & 157 & 41 & 26,1 \\
\hline Mg. migonei & - & - & - & 1 & 1 & 100,0 & - & - & - & 1 & 1 & 100,0 \\
\hline Ny. intermedia & - & - & - & - & - & - & 74 & 12 & 16,2 & 74 & 12 & 16,2 \\
\hline Total & 129 & 14 & 10,85 & 29 & 28 & 96,6 & 74 & 12 & 16,2 & 232 & 54 & 23,3 \\
\hline
\end{tabular}

Test. Testadas; Reag. $=$ reagentes.

$\mathrm{Na}$ tabela 19 são apresentados os números e as freqüências de fêmeas de flebotomíneo testadas e a de reagentes, segundo localidade e o hospedeiro. No PEC foram identificados positivos para sangue humano, suíno, cão e rato. No bairro Serra , a positividade foi observada em todos os tipos de sangue analisados (humano, galinha, suíno, cão e rato). Em Cotia foi observado repasto positivo para sangue humano e de galinha.

Também foram observados flebotomíneos com repasto misto: PEC; 1 fêmea de Pi. fischeri reativa para rato e humano; Cotia: 1 fêmea de Pi. fischeri (humano e galinha) e no bairro Serra, duas fêmeas de $\mathrm{Ny}$. intermedia (uma, para galinha e suíno e a outra, para rato e suíno). Portanto, no total das reagentes, $7,4 \%$ tiveram repasto misto. 
Tabela 19 - Resultados do teste ELISA para repasto sanguíneo em fêmeas de Nyssomyia intermedia (Bairro Serra - Iporanga), Pintomyia fischeri e Migonemyia migonei (PEC e Cotia), SP.

\begin{tabular}{lcccccccccc}
\hline \multicolumn{1}{l}{ Fonte de sangue: $\mathrm{n}$ - de positivos (\%) } \\
\begin{tabular}{lcccccccccc}
\multicolumn{1}{l}{ Local de } \\
coleta
\end{tabular} & Testados & Positivos & Negativos & Humano & Galinha & Suíno & Cão & Rato & Misto \\
\hline PEC & 129 & 14 & 115 & 9 & 0 & 2 & 2 & 1 & 1 \\
& $(55,6)$ & $(10,85)$ & $(89,15)$ & $(6,98)$ & $(0,0)$ & $(1,55)$ & $(1,55)$ & $(0,76)$ & $(0,7)$ \\
Bairro & 74 & 12 & 62 & 2 & 5 & 8 & 2 & 4 & 2 \\
Serra & $(31,9)$ & $(16,2)$ & $(83,8)$ & $(2,7)$ & $(6,7)$ & $(10,8)$ & $(2,7)$ & $(5,4)$ & $(2,7)$ \\
Cotia & 29 & 28 & 1 & 1 & 28 & 0 & 0 & 0 & 1 \\
& $(12,5)$ & $(96,55)$ & $(3,45)$ & $(3,45)$ & $(96,55)$ & $(0,0)$ & $(0,0)$ & $(0,0)$ & $(3,5)$ \\
\hline Total & 232 & 54 & 178 & 12 & 32 & 10 & 4 & 5 & 4 \\
& $(100)$ & $(23,3)$ & $(76,7)$ & $(5,17)$ & $(13,8)$ & $(4,3)$ & $(1,7)$ & $(2,2)$ & $(1,7)$ \\
\hline
\end{tabular}

Pi. fischeri apresentou maior número de positivos para repasto em galinha seguido de humano, $\mathrm{Ny}$. intermedia apresentou maior número de positivos para suíno seguido de galinha e 1 exemplar da espécie Mg. migonei somente foi positivo para galinha (Tabela 20).

Tabela 20 - Resultados positivos o teste ELISA para repasto sanguíneo para Nyssomyia intermédia, Pintomyia fischeri e Mg. Migonei (PEC,COTIA e bairro SerraPETAR), SP.

\begin{tabular}{llllllll}
\hline & Humano & Suíno & Galinha & Cão & Rato & Misto & Total \\
\hline PI. fischeri & 10 & 2 & 27 & 2 & 1 & 2 & 43 \\
Ny. intermedia & 2 & 8 & 5 & 2 & 4 & 2 & 10 \\
Mg. migonei & 0 & 0 & 1 & 0 & 0 & 0 & 1 \\
\hline Total & 14 & 10 & 33 & 4 & 5 & 4 & 54 \\
\hline
\end{tabular}




\section{DISCUSSÃO}

O conhecimento do sangue ingerido por flebotomíneos em conjunto com outras informações relativas à capacidade vetora, oferecem importante subsídio para a avaliação do papel desempenhado por uma determinada espécie de flebotomíneo no processo de transmissão de patógenos (FERREIRA, 1945; HAOUAS et al., 2007), bem como pode auxiliar no emprego de medidas adequadas ao controle desses insetos (DIAS-SVERSUTTI et al., 2007). O teste ELISA pode ser uma importante ferramenta a ser utilizada na pesquisa do sangue ingerido pelos flebotomíneos e temse mostrado eficiente por apresentar maior sensibilidade e especificidade em relação ás outras técnicas, permitindo o processamento e investigação de um grande número de amostras, fato que contribui no estudo epidemiológico (BEIER, 1988).

$\mathrm{Na}$ padronização do teste ELISA, no que diz respeito a determinação da sensibilidade do mesmo, com relação ao sangue de hospedeiros, verificou-se que 0 teste apresentou bom desempenho para identificação de todos os tipos de sangue analisados, com a melhor performance para humano e galinha, seguida da de cão, porco e rato, tal como os resultados obtidos para culicídeos por VICENTIN (2006) e LAPORTA (2007) .

Conforme recomendação de BEIER (1988), as diluições das amostras de sangue de um determinado hospedeiro foram confrontadas com diluições de uma amostra de sangue heterólogo para comprovar a sensibilidade e especificidade do teste, tendo sido observado ótimo desempenho dos anti-soros e conjugados, permitindo trabalhar em altas diluições de anti-soros e conjugados de humano, galinha, suíno e cão com exceção do anti-soro e conjugado de rato.

$\mathrm{Na}$ análise do tempo de digestão, a técnica apresentou elevada sensibilidade e especificidade. Foi possível a identificação de sangue ingerido até 36 horas após o repasto do sangue humano. MARASSÁ et al. (2004), utilizando sistema avidinabiotina do ELISA indireto em fêmeas de Lutzomyia longipalpis, detectaram sangue até 24 horas pós-repasto.

O uso do método de ELISA indireto de captura de CHOW et al. (1993) com modificações introduzidas por VICENTIN (2006), e neste estudo, adaptada para uso 
em flebotomíneos, provou ser capaz de detectar ínfimas quantidades de sangue ingerido por esses insetos, empregando-se pequenas quantidades de reagentes e tempo reduzido entre as suas etapas. Revelou-se, portanto, um teste simples de ser utilizado, pouca quantidade de reagentes, o que aumenta a sua reprodutibilidade, como se espera de um teste para uso em um laboratório de saúde pública.

Alguns problemas ocorrem na rotina laboratorial quando se emprega o teste imunoenzimático (ELISA), seja para detecção de anticorpos como para a detecção de antígenos, um deles é a correta determinação do ponto de corte, a fim de se evitar a presença de resultados falsos positivos e negativos nos ensaios, utilizou 3 desviospadrão, conforme recomendado por VICENTIN (2006). Assim como foi utilizado anteriormente, para se evitar a existência de reações cruzadas entre os testes, optouse por padronizar cada anti-soro, achando a concentração ótima, aquela cujo risco do sangue reagir com mais de um anti-soro é praticamente nulo.

Após a padronização da técnica, flebotomíneos de campo foram testados e os resultados revelaram importantes aspectos para 0 entendimento do contexto epidemiológico das áreas de origem dos mesmos. Dentre as 232 fêmeas testadas das três localidades, havia 3 espécies, $N y$. intermedia, Mg. migonei com envolvimento como vetoras de leishmaniose tegumentar e Pi. fischeri, que embora ainda não tenha sido encontrada com infeção natural pelo agente desta parasitose, o seu alto grau de antropofilia, predominância em áreas endêmicas e a infecção experimental tem levado os autores a suspeitarem de sua participação na transmissão desta doença (RANGEL et al., 2003). Ny. intermedia, s.lat., foi apontada como o principal vetor em ambiente domiciliar, devido a sua dominância em relação às outras espécies, ao comportamento antropofílico e ao fato de ter sido encontrada sua infecção natural por flagelados (FORATTINI, 1953 e 1973; FORATTINI et al., 1972 e 1976; GOMES, 1994 e GOMES et al., 1980, 1982, 1986). Mg. migonei com ampla dispersão no Estado de São Paulo, apresentou correlação significativa com o coeficiente de incidência da leishmaniose tegumentar, sendo apontada como vetor secundários, (CAMARGONEVES et al., 2002). Assim o teste aqui padronizado poderá contribuir para se ampliar o conhecimento do comportamento dessa espécie em relação ao hábito 
alimentar e conseqüentemente de possíveis vertebrados envolvidos no ciclo da leishmaniose tegumentar.

No PEC, $14 / 129(10,85 \%)$ das fêmeas analisadas foram positivas para os diversos tipos de sangue, indicando ecletismo da espécie quanto ao hábito alimentar nesta localidade, especialmente em relação ao humano (Tabela 19). A proximidade do ponto de coleta de residências e as freqüentes incursões de pessoas à localidade, explicam esses resultados. Apesar de não haver chiqueiro, a reatividade para antisoro de suíno pode ser um indicativo da presença de suínos selvagens (cateto) nas matas. No bairro Serra, houve maior ecletismo em relação PEC, foram 12/74 (16,2\%) as fêmeas reagentes, destacando-se o suíno. Provavelmente devido às coletas terem sido feitas em um peridomicílio com a presença de um anexo que se dividia na função de galinheiro e chiqueiro. Em Cotia 28/29 (96.55\%) (Tabela 19) das fêmeas reagiram com anti-soro de galinha. Resultado esperado, uma vez que a coleta se deu em galinheiro. Os resultados também mostram a atratividade que esses animais exercem nos flebotomíneos. As fêmeas dos flebotomíneos vetores são atraídas pela presença de animais domésticos no peridomicílio, vendo nesses a possibilidade de alimentação fácil (CAMARGO-NEVES et al., 2002). Em geral a positividade com sangue humano e repasto misto foi maior do que aquelas obtidas com sangue suíno, na localidade PEC e o inverso no bairro Serra (PETAR) que teve repasto misto para rato e suíno. A mistura de sangue nos mosquitos pode envolver alimentação em vários espécimes diferentes de hospedeiros conforme indicado por BOREHAM e GARRETT-JONES (1972).

Do total de positivos para repasto sanguíneo, $P i$. fischeri foi a espécie que mais se destacou $41 / 54$ (75,9\%), para as localidades de Cotia $27 / 54(50,0 \%)$ e PEC 14/54 $(25,9 \%)$. Nyssomyia intermedia $12 / 54(22,2 \%)$ dos positivos ocorrendo apenas no bairro Serra (PETAR) (Tabela 20).

Na Grande São Paulo, que engloba Cotia e Cantareira, a espécie com maior número de exemplares testados foi $P$ i. fischeri, respectivamente, $27 / 54(50,0 \%)$ e $41 / 54$ (75,9\%), e além desta, apenas uma fêmea de Mg. Migonei (Tabela 20). Essa predominância de espécimes de $P i$. fischeri testados é reflexo da sua freqüência também predominante nas capturas feitas em Cotia por SILVA, (2006) e na 
Cantareira por Barretto (1943) e que estão sendo realizadas atualmente (J.C. Moschim, informação pessoal). No bairro Serra, apenas fêmeas $N y$. intermedia foram testadas, das quais $22,2 \%$ (12/54) foram reagentes (Tabela 20). Nessa localidade embora esta espécie tenha predominado em coletas realizadas por GALATI et al. (2009), Ny. neivai também foi capturada com freqüências relativamente elevadas, porém, nenhuma fêmea fez parte da amostra obtida com sangue.

Alguns autores empregaram a técnica imunoenzimática para o conhecimento de fonte alimentar de flebotomíneos. Através do teste ELISA direto, NGUMBI et al. (1992), investigaram no distrito de Baringo no Kenia, o sangue ingerido por 376 de flebotomíneos, destes 176 (46,8\%) foram positivos para repasto sanguíneo, sendo $81 \%$ em Phlebotomus martini, 6\% em Sergentomyia clydei, 3,5\% em S. adleri, 2,8\% em S. antennatus, $2,2 \%$ em $S$. schwetzi. $P$. martini apresentou repasto positivo para todos os 16 hospedeiros testados com maior destaque para cabra $(36,4 \%)$, coelho $(29,0 \%)$ e humano(11,4\%), 12 repastos mistos com 2 hospedeiros diferentes, destacando os que obtiveram repasto misto com humanos (cabra, coelho e esquilo). Esta espécie é um vetor conhecido de leishmaniose visceral (calazar) na área de estudo e se alimentou em 12 das 13 espécies de hospedeiros testados, dos quais 3 são possíveis reservatórios de Leishmania donovani.

O emprego do teste de imunoenzimático indireto, ELISA de captura, com a introdução do sistema biotina-avidina, foi utilizado para identificação de sangue ingerido por 425 fêmeas ingurgitadas de flebotomíneos da espécie Phlebotomus perniciosus coletados em diferentes localidades da Espanha por COLMENARES et al., (1995), e permitiu a quantificação de sangue ingerido em amostras com diferentes períodos de pós-ingestão. Foram identificados em 16 tipos de hospedeiros nas 253 amostras de sangue positivas, 31 apresentaram repastos mistos para 2 diferentes hospedeiros, destacando cabra/ovelha $38,7 \%$, e 8 deles em três hospedeiros, a maioria em vaca/cabra/ovelha $9,6 \%$, portanto $15,4 \%$ de repastos mistos. Valor estes bem acima do que obtivemos neste estudo $(7,4 \%)$. Possivelmente este valor menor foi devido à coleta em abrigos de animais domésticos, sobretudo em Cotia onde se obteve o maior percentual de reagentes. 
Utilizaram o mesmo método, MARASSÁ et al., (2006), para identificar o hábito alimentar em aves de fêmeas de Lutzomyia longipalpis e de Lutzomyia almerioi coletadas com armadilhas automáticas luminosas em galinheiro no peridomicílio no Assentamento Guaicurus na Serra da Bodoquena, MS, área de ocorrência de casos humanos de leishmaniose tegumentar e leishmaniose visceral canina. Foram 83 os exemplares ingurgitados testados, 57 de Lu. longipalpis e 26 de Lu. almerioi, obtendo $72 \%$ de reagentes para ave em Lu. longipalpis e $96 \%$ em Lu. almerioi o que evidenciou maior ecletismo da primeira espécie, aspecto relevante, uma vez que esta é a principal vetora do agente da leishmaniose visceral. Os dados destas duas espécies são próximos aos encontros para $\mathrm{Pi}$. fischeri em Cotia, onde a coleta ocorreu em galinheiro.

Os resultados obtidos com as fêmeas selvagens neste estudo reforçam a validade do teste padronizado, uma vez que houve predomínio de reatividade para sangue humano no PEC, onde as fêmeas foram capturadas com armadilhas de Shannon, instalada em peridomicílio, tendo o homem também como atratividade. No bairro Capuava, Cotia, onde as fêmeas foram capturadas com CDC instalada em galinheiro, $96,6 \%$ das fêmeas foram reagentes para ave. Todavia, foi possível detectar um repasto misto com humano. No bairro Serra, Iporanga, com as armadilhas CDCs instaladas em um abrigo de animais que se dividia em chiqueiro e galinheiro, houve reatividade para suíno e aves. Também se detectou repasto misto com rato.

Técnicas moleculares, como a Reação de Polimerase em cadeia (PCR), vem sendo utilizadas para identificação do sangue ingerido por flebotomíneos apresentando a vantagem de detectar quantidades bem inferiores de sangue quando comparadas com as de ELISA, além da possibilidade de identificar uma maior diversidade de hospedeiros sem seleção a priori, a infeç̧ão por parasitas e também a espécie do flebotomíneo.

Utilizando um método de PCR específico para vertebrado, combinado com "reverse line blot analysis", ABBADI et al., (2008) identificou o sangue ingerido por fêmeas de flebotomíneos como vetores de leishmanioses. Os oligonucleotídeos 
espécie-específicos foram covalentemente ligados à membranas de nylon e biotiniladas, tendo como resultado, produtos do PCR mitocondrial do gene citocromo b. Esta combinação identificou o sangue ingerido em até 96 horas após o repasto, contendo mínimas quantidades de DNA $(>0,1 \mathrm{pg})$. A prova específica discriminou entre as espécies de hospedeiros em diversas áreas de estudo. A origem do sangue foi identificada em 68 das 89 detectou em mosquitos silvestres (76\%). Repastos mistos foram identificados para $15(17 \%)$ deles.

Em inquérito entomológico, TORINA et al. (2008) procuraram detectar a presença do parasito leishmânia em flebotomíneos de seis províncias. Foram coletadas 20.346 flebotomíneos utilizando armadilhas do tipo "black light" em oito fazendas de gado e ovelhas. Prevaleceram Phlebotomus perfiliewi $(51,60 \%) \mathrm{P}$. perniciosus $(24,03 \%)$ e Segentomyia sp., (24,03\%). Entre as 11.441 fêmeas coletadas, $284(2,70 \%)$ estavam com ovos e $708(6,74 \%)$, ingurgitadas. Um total de 194 com ovos, 274 ingurgitadas e 254 sem de evidência de ingestão de sangue foram analisadas para $L$. infantum por PCR, mostrando que $9,79 \%$ das fêmeas com ovos, $5,84 \%$ das alimentadas com sangue e $5,51 \%$ das fêmeas não ingurgitas foram positivas para Leishmania sp.

Outro protocolo baseado em tecnologia de estabilização e armazenamento do DNA foi utilizado por SANT'ANNA et al. (2008), onde os autores obtiveram identificação de fontes de alimentação de flebotomíneos da espécie Lu. longipalpis por meio do PCR subseqüente, bem como a deteç̧ão de parasitas. Esta técnica revelou que $53,6 \%$ dos flebotomíneos capturados nos quintais de casas em no município de Teresina (Brasil) tiveram repasto em galinhas.

Os autores HAOUAS et al. (2007) desenvolveram ferramenta molecular para a identificação das refeições de sangue de flebotomíneos pela ampli o específica e seqüenciamento do sangue ingerido derivado de única cópia prepronociceptina (PNOC gene), que é usado como um alvo em estudos filogenéticos de mamíferos. Flebotomíneos foram identificados simultaneamente com a identificação do repasto sanguíneo, por meio da análise de um locus ribossomal. Depois de uma avaliação sistemática da sensibilidade e especificidade da reação em cadeia da polimerase para amplificação do gene PNOC, usando flebotomíneos alimentados de sangue humano, 
testaram flebotomíneos capturados na natureza. O estudo apresentou contribuições importantes para a descoberta de novos reservatórios de Leishmania sp. e uma melhor compreensão do complexo ciclo de vida do parasita.

Em um assentamento rural da capital de Trujillo, Venezuela, HERNÁNDEZ et al. (2006) estudaram a capacidade potencial do cão doméstico (Canis familiaris) como uma fonte de infecção para Lutzomyia youngi, uma das espécies de flebotomíneo mais abundantes na área de estudo e cuja atividade vetorial doméstica havia sido comprovada. Os cães com lesões cutâneas sugestivas de leishmaniose tegumentar americana (LTA) e confirmação parasitológica de infecção, foram selecionados para xenodiagnóstico, com flebotomíneos silvestres de uma área de livre LTA, se alimentando sobre a superfície do corpo do animal. Os tratos intestinais dos insetos foram dissecados 5 dias após a refeição de sangue para pesquisa por flagelados, $A$ identificação parasitológica foi realizada pela técnica de multiplex-PCR. 455 em fêmeas ingurgitadas de sangue de dois cães em três ensaios diferentes; formas promastigotas foram encontradas em 4 (0,88\%) das amostras em apenas uma ocasião. PCR identificou o DNA de Leishmania subgênero Viannia. O estudo demonstrou que cão doméstico tem o potencial de ser um fator de risco no ciclo de transmissão LTA.

Alguns autores relatam que os insetos possuem, em seus tecidos inibidores que podem diminuir a eficiência da reação de PCR, sendo que este estão presentes majoritariamente em seus exoesqueletos, cabeça e tórax PAIVA (2007).

Apesar das vantagens que os protocolos moleculares apresentam na identificação do sangue ingerido pelos flebotomíneos, sua implantação para uso na rotina dos laboratórios, esbarra no alto custo com equipamentos e reagentes. Sendo melhor utilizado para pesquisas científicas.

A técnica de ELISA realmente pode ser utilizada em laboratórios de Saúde Pública tanto na rotina quanto em projetos de pesquisa, se tornado grande aliado a compreensão de aspectos epidemiológicos importantes das leishmanioses, porém é importante ressaltar que ainda é um teste caro. Por outro lado seu alto rendimento tanto em relação aos reagentes como no que diz respeito a quantidade de amostras que são processadas em cada teste. 


\section{CONCLUSÃO}

- O teste de ELISA padronizado neste estudo foi capaz de distinguir cada uma das fontes de sangue para as fêmeas de flebotomíneos: humano, galinha, cão, suíno e rato.

- Os ensaios de padronização, quantidade de sangue ingerido e de tempo de digestão comprovaram a sensibilidade e especificidade do teste de ELISA indireto.

- Foi possível detectar a fonte do sangue ingerido até 36 horas pós- repasto em fêmeas criadas em laboratório.

- O teste padronizado identificou sangue ingerido nas fêmeas de flebotomíneos com percentuais do tipo de hospedeiros compatíveis com o método e local de coleta. Ou seja com armadilha de Shannon, houve predomínio de humanos, e nas CDCs instaladas em galinheiro, predomínio quase que absoluto para sangue de ave e nas CDCs instalada em abrigo representado misto (chiqueiro/galinheiro), houve reatividade para suíno e ave.

- O teste também foi capaz de detectar repastos mistos.

- O teste mostrou com sensibilidade, especificidade, bom rendimento e de fácil execução, de modo a poder ser utilizado em laboratório de saúde pública. 
8. REFERÊNCIAS BIBLIOGRÁFICAS

ABBADI, I., CUNIO, R., WARBURG, A. Identification of blood meals imbibed by Phlebotomine snd flies using cytochrome b PCR and Reverse Line Blotting. Vector Borne Zoonotic Dis. 008 Oct 30. 2008

ALEXANDER, B.; USMA, M.C. Potencial source of the phlebotomine sandfly Lutzomyia youngi (Diptera: Psycodidae) in a Colombiam coffee plantation. Annals of Tropical Medicine and Parasitology, v. 88, p. 543-549, 1994.

ANDRADE-FILHO, J.D.; GALATI, E.A.B.; FALCÃO, A.L. Nyssomyia intermedia (Lutz e Neiva, 1912) and Nyssomyia neivai (Pinto, 1926) (Diptera: Psychodidae: Phlebotominae) geographical distribution and epidemiological importance. Memórias do Instituto Oswaldo Cruz, v. 102, n. 4, p. 481-487, 2007.

ARAGÃO, H.B. 1922. Transmissão de leishmaniose no Brasil pelo Phlebotomus intermedius. Brasil Médico, v 36, p 129 -130, 1922.

BARRETTO, M.P.Contribuição para o estudo da biologia dos flebótomos em condições experimentais (Diptera, Psychodidae). 1942.162 p. Tese (Doutoramento em Parasitologia) - Faculdade de Medicina da Universidade de São Paulo, São Paulo, 1942.

BARRETTO, M.P. Observações sobre a biologia, em condições naturais, dos flebótomos do Estado de São Paulo (Diptera, Psychodidae). 1943. 162 p. Tese (Concurso à Docência-Livre em Parasitologia) - Faculdade de Medicina da Universidade de São Paulo, São Paulo, 1943.

BEIER, J.C. et al. Bloodmeal identification by direct enzyme-linked immunosorbent assay (ELISA), tested on Anopheles (Diptera: Culicidae) in Kenya. Journal of Medical Entomology, v. 25, n. 1, p. 9-16, jan. 1988.

BOREHAM, P.F.L. Serological identification of arthropod bloodmeals and its application. PANS, v. 18, p. 205, 1972.

BURKOT, T.R.; GOODMAN, W.G.; DeFOLIART, G.R. Identification of mosquito blood meals by enzyme-linked immunosorbent assay. The American Journal of Tropical Medicine and Hygiene, v. 30, n. 6, p. 1336-1341, 1981.

CAMARGO-NEVES, V.L.C; GOMES, A.C; ANTUNES, J.F.L . Correlação da presença de espécies de flebotomíneos (Diptera: Psychodidae) com registros de casos da leishmaniose tegumentar americana no Estado de São Paulo, Brasil. Revista da Sociedade Brasileira de Medicina Tropical, v 35, p 299-306, 2002.

CAMARGO-NEVES, V.L.C. et al. Leishmaniose tegumentar americana no Estado de São Paulo: um breve histórico e a descrição das espécies de flebotomíneos. In: 
SUCEN. Suplemento 1 do Boletim Epidemiológico Paulista. São Paulo, v. 3, ago. 2006.

CAMERON, M,M. et al. Sugar meal sources for phlebotomine sandflies Lutzomyia longipalpis in Ceará State, Brazil. Medical and Veterinary Entomology, v. 9, n. 3, p. 263-272, jul. 1995.

CASANOVA, C. et. al. Natural Lutzomyia intermedia (Lutz \& neiva) infection in the valley of the Mogi Guaçú river, state of São Paulo, Brazil. Boletín de la Dirección de Malariología y Saneamiento Ambiental, v 35,(supl 1), p 77 - 84, 1995.

CASANOVA, C.; NATAL, D.; SANTOS, F.A.M. Survival, population size and gonotrophic cycle duration of Nyssomyia neivai (Diptera: Psychodidae) at an endemic area of American cutaneous leishmaniasis in southern Brazil. Journal of Medical Entomology, v 46, p 42 - 50, 2009.

CHOW, E.; WIRTZ, R. A.; SCOTT, R.W. Identification of blood meals in Aedes aegypti by antibody sandwich enzyme-linked immunosorbent assay. Journal of the American Mosquito Control Association, v. 9, n. 2, p. 196-205, jun. 1993.

COLMENARES, M. de; et al. Identification of blood meals of Phlebotomus perniciosus (Diptera: Psychodidae) in Spain by a competitive enzyme-Linked immunosorbent assay biotin/avidin method. Journal of Medical Entomology, v. 32, n. 3, p. 229-233, mai. 1995.

COMER, J.A.; IRBY. W.S.; KANANAUGH, D.M. Hosts of Lutzomyia shannoni (Diptera: Psychodidae) in relation to vesicular stomatitis virus on Ossabaw Island, Georgia, USA. Medical and Veterinary Entomology, v. 8, n. 4, p. 325-330, out. 1994.

COORDENADORIA DE GEOPROCESSAMENTO E CARTOGRAFIA, INSTITUTO FLORESTAL, 2008.

DIAS, A.R. et al. Parque Estadual da Cantareira: a maior floresta urbana nativa do mundo. São Paulo, 2000. Disponível em: <http://www.florestsp.br/unidades.htm>. Acesso: 17/04/2009.

DIAS-SVERSUTTI, A.C. et al. Estudo preliminar da preferência alimentar de Nyssomyia neivai (Pinto) e Nyssomyia whitmani (Antunes e Coutinho) (Diptera: Psychodidae) em Área Rural do Paraná. Neotropical Entomology, v 36, n 1, p 953 959, 2007.

FERREIRA, E.S.C. A reação das precipitinas aplicadas aos dípteros do gênero Phlebotomus. Anais do Instituto de Medicina Tropical, v. 2, p. 187-196, 1945. 
FORATTINI, O.P. Nota sobre criadouros naturais de flebótomos em dependências peridomiciliares, no Estado de São Paulo. Arquivos da Faculdade de Higiene e Saúde Pública, v. 7, p. 157-67, 1953.

FORATTINI, O.P.; OLIVEIRA, O. Um foco de leishmaniose tegumentar na zona sul do Estado de São Paulo, Brasil. Arquivos da Faculdade de Higiene e Saúde Pública, v. 11, p. 23-34, 1957.

FORATTINI, O.P. et al. Infecções naturais de mamíferos silvestres em área endêmica de leishmaniose tegumentar do Estado de São Paulo, Brasil. Revista de Saúde Pública, v. 6, p. 255-261, 1972.

FORATTINI, O.P. Entomologia Médica. IV: Psychodidae. Phlebotominae. Leishmanioses. Bartolonese. São Paulo: Edgard Blücher, 1973. 658 p.

FORATTINI, Oswaldo Paulo et al. Observações sobre a transmissão da leishmaniose tegumentar do Estado de São Paulo, Brasil. Revista de Saúde Pública, v. 10, p. 31 $43,1976$.

GALATI, E.A.B. Classificação de Phlebotominae - Morfologia e Taxonomia. In: RANGEL, E.F.; LAISON, R. Flebotomíneos do Brasil. 1. ed. Rio de Janeiro: Editora Fiocruz, 2003. p. 23-51.

GALATI, E.A.B. et al. Attractiveness of Black Shannon Trap for Phlebotomines. Memórias do Instituto Oswaldo Cruz, v. 96, n. 5, p. 641-647, 2001.

GALATI, E.A.B. et al. Phlebotomines (Diptera, Psychodidae) in the Speleological Province of the Ribeira Valley: 3. Serra district - area of hostels for tourists who visit the Parque Estadual do Alto Ribeira (PETAR), state of São Paulo, Brazil. Revista Brasileira de Entomologia 2009. (aceito para publicação).

GOMES, A.C. et al. Aspectos ecológicos da leishmaniose tegumentar americana. 1. Estudo experimental da freqüência de flebotomíneos em ecótopos artificiais com referência especial a Psychodopygus intermedius. Revista de Saúde Pública, v. 14, p. 540-556, 1980.

GOMES, A.C. et al. Aspectos ecológicos da leishmaniose tegumentar americana. 2. Ecótopo artificial como abrigo de Psychodopygus intermedius e observações sobre alimentação e reprodução sob influência de fatores físicos naturais. Revista de Saúde Pública, v. 16, p. 149-159, 1982.

GOMES, A.C. et al. Ecological aspects of American cutaneous leishmaniasis. 4. Observations on the endophilic behavior of sandfly and the vectorial role of Psychodopygus intermedius in the Ribeira Valley region of the São Paulo State, Brazil. Revista de Saúde Pública, v. 20, p. 280-287, 1986. 
GOMES, A.C. Perfil epidemiológico da leishmaniose tegumentar no Brasil. Anais Brasileiros de Dermatologia, v. 67, n. 2, p. 55-60, 1992.

GOMES, A.C. Sand fly vectorial ecology in the State of São Paulo. Memórias do Instituto Oswaldo Cruz, v. 89, p. 457-460, 1994.

HAOUAS, N. et al. Development of a molecular tool for the identification of Leishmania reservoir hosts by blood meal analysis in the insect vectors. American Journal of Topical Medicine and Higyene. v. 77, n. 6, p. 1054 -1059, dec. 2007.

HERNÁNDEZ, D. et al. Dog (Canis familiaris) infectivity to Lutzomyia youngi in Trujillo, Venezuela. Biomedica. v. 26, n. 1, p. 242-248. Oct. 2006.

KARMANN, I.; FERRARI, J.A. Carste e cavernas do Parque Estadual Turístico do Alto Ribeira (PETAR), sul do Estado de São Paulo. 1999. Disponível em: $<$ www.unb.br/sigep $>$.

KING, W.V.; BULL, C.G. The blood feeding habits of malaria-carrying mosquitoes. American Journal of Hygiene, v. 3, p. 491-496, 1923.

KOBAYASHI, K.M. Antropofilia e polimorfismo de genes mitocondriais em populações de Aedes scapularis (Rondani) em três regiōes hidrográficas do Estado de São Paulo. 2004. 107 p. Tese (Doutorado em Epidemiologia) - Faculdade de Saúde Pública da Universidade de São Paulo, São Paulo, 2004.

KREIKE, J.; KAMPFER, S. Isolation and characterization of human DNA from mosquitoes (Culicidae). International Journal of Legal Medicine, v. 112, n. 6, p. 380-382, 1999.

LAINSON, R.; SHAW, J.J. The role of animals and the epidemiology of South American Leishmaniasis. In: LUMSDEN, W.H.R.; EVANS, D.A. The biology of the Kinetoplastida. Londres: Academic Press, v. 2, 1979.

LAINSON, R.; SHAW, J J. New World leishmaniasis, In: Cox FEG, Kreier JP, Wakelin D, editors. Topley \& Wilson's Arnold. Microbiology and Microbial Infections, Parasitology, London, Sydney, Auckland; 2005. p.313-349.

LAPORTA, G.Z. Ecologia de Culex quinquefasciatus e de Culex nigripalpus no Parque Ecológico do Tietê, São Paulo, Brasil. 2007. 115 p. Dissertação (Mestrado em Epidemiologia) - Faculdade de Saúde Pública da Universidade de São Paulo, São Paulo, 2007.

MAGNARELLI, L.A.; MODI, G.B. Calorie determinations of phlebotomine sandflies Rio Ribeira de Iguape. Boletim Científico, 1988. 
MARASSÁ, A.M.; CONSALES, C.A.; GALATI, E.A.B. Padronização da técnica imunoenzimática do ELISA de captura, no sistema avidina-biotina para a identificação de sangue ingerido por Lutzomyia (Lutzomyia) longipalpis (Lutz \& Neiva, 1912). Revista da Sociedade Brasileira de Medicina Tropical, v. 37, n. 6, p. 441-446, nov./dez. 2004.

MARASSÁ, A.M., CONSALES, C.A., GALATI, E.A.B. Identificação do sangue ingerido por Lutzomyia (Lutzomyia) longipalpis (Lutz \& Neiva, 1912) e Lutzomyia (Lutzomyia) almerioi (Galati \& Nunes, 1999) pela técnica imunoenzimática do ELISA de captura, no sistema avidina-biotina. Revista da Sociedade Brasileira de Medicina Tropical, v. 39, n. 2, p. 183-186, mar./abr. 2006.

MARCONDES, C.B.; LOZOVEI, A.L.; VILELA, J.H. Distribuição geográfica de flebotomíneos do complexo Lutzomyia intermedia (Lutz \& Neiva, 1912) (Díptera: Psychodidae). Revista da Sociedade Brasileira de Medicina Tropical, v. 31, n. 1, p. 51-58, jan./fev. 1998.

MINISTÉRIO DA SAÚDE. Casos de Leishmaniose Tegumentar Americana. Brasil, Grandes Regiōes e Unidades Federadas. 1990 a 2008. Brasília, 2008. Disponivel em: $<$ hittp://portal.saude.gov.br/portal/arquivos/pdf/CASOS_CONF_LTA .pdf>. Acesso em: $22 / 06 / 2008$.

MONTES, J. Fauna de Culicidae da Serra da Cantareira, São Paulo, Brasil. Revista de Saúde Pública, v. 39, n. 4, p. 578-584, 2005.

MUKABANA, W.R.; TAKKEN, W.; KNOLS, B.G. Analyis of arthropod bloodmeals using molecular genetic markers. Trends in Parasitology, v. 18, n. 11, p. 505-509, nov. 2002.

NGUMBI, P.M. et al. Identification of phlebotomine sandfly bloodmeals from Baringo district, Kenya, by direct enzyme-linked immunosorbent assay (ELISA). Medical and Veterinary Entomology, v. 6, n. 4, p. 385-388, out. 1992.

NIEBYLSKI, M.L. et al. Blood hosts of Aedes albopictus in the United States. Journal of the American Mosquito Control Association, v. 10, n. 3, p. 447-450, set. 1994.

PAIVA, B.R. et al. Padronização de condiçōes para a detecção de DNA de Leishmania spp. em flebotomíneos (Díptera: Psychodidae) pela reação em cadeia da polimerase. Cadernos de Saúde Pública, v. 23, n. 1, p. 87-94, 2007.

PESSÔA, S.B.; COUTINHO, J.O. Infecção natural e experimental dos flebótomos pela Leishmania braziliensis, no Estado de São Paulo. O Hospital, v. 20, n. 1, p. 25-35, 1941.

PESSÔA, S.B.; MARTINS, A.V. Parasitologia médica. 11. ed, Rio de Janeiro: Guanabara Koogan, 1988. p 523. 
PITA-PEREIRA, D. et. al. 2005. Identification of naturally infected Lutzomyia intermedia and Lutzomyia migonei with Leishmania (Viannia) braziliensis in Rio de Janeiro (Brazil) revealed by a PCR multiplex non-isotopic hybridisation assay. Transaction of the Royal Society of Tropical Medicine and. Hygiene, v 99, p 905 913, 2005.

QUINNELL, R.J.; DYE, C.; SHAW, J.J. Host preferences of phlebotomine sandfly Lutzomyia longipalpis in Amazonian Brazil. Medical and Veterinary Entomology, v. 6, n. 3, p. 195-200, jul. 1992.

RANGEL EF, LAINSON R. Transmissores de leishmaniose tegumentar americana. In RANGEL EF, LAINSON R (orgs.). Flebotomíneos do Brasil. Rio de Janeiro: Fiocruz; 2003. 291-309p.

RICE, J.B.; BARBER, A.M. Malaria studies in Greece. A modification of the UlenhuthWeldanz precipitin test for determining the source of bloodmeals in mosquitoes and other insects. The Journal of Laboratory and Clinical Medicine, v. 20, p. 876-883, 1935.

RUBIO-PALIS, Y. et al. Host choice of anopheline mosquitoes in a malaria endemic area of western Venezuela. Medical and Veterinary Entomology, v. 8, n. 3, p. 275280, jul. 1994.

SANT'ANNA, M.R. et al. Blood meal identification and parasite detection in laboratoryfed and field-captured Lutzomyia longipalpis by PCR using FTA databasing paper. Acta Tropica, v. 107 n.3, p. 230-237; Jun. 2008.

SANTOS, O.O. dos. Conhecimento atual sobre técnicas de determinação do hábito alimentar de artrópodes vetores. $1990.48 p$. + Anexos. Dissertação (Mestrado em Epidemiologia) - Faculdade de Saúde Pública da Universidade de São Paulo, São Paulo, 1990.

SARAIVA. L. et al. Natural Infection of Lutzomyia neivai and Lutzomyia sallesi (Diptera: Psychodidae) by Leishmania infantum chagasi in Brazil. Journal of Medical Entomology, v 46, n 5, p $1159-1163,2009$.

SAVAGE, H.M. et al. Host-feeding patterns of Aedes albopictus (Diptera: Culicidae) at a temperate North American site. Journal of Medical Entomology, v. 30, n. 1, p. 2734, jan. 1993.

SECRETARIA DE ESTADO DA SAÚDE DE SÃO PAULO - CENTRO DE VIGILÂNCIA EPIDEMIOLÓGICA "ALEXANDRE VRANJAC" (CVE). Manual de Vigilância Epidemiológica. Leishmaniose Tegumentar Americana - Normas e Instruçōes. São Paulo, 1995. 28 p.

SECRETARIA DE ESTADO DA SAÚDE DE SÃO PAULO. CENTRO DE VIGILÂNCIA EPIDEMIOLÓGICA "ALEXANDRE VRANJAC" (CVE). Leishmaniose tegumentar. São Paulo, 2009. Disponível em: <http://www.cve.saude.sp.gov.br/ht 
m/zoo/lta_gve.htm>.Acesso em: 01 out. 2009.

SERVICE, M.W.; VOLLER, A.; BIDWELL, D.E. The enzyme-linked immunosorbent assay (ELISA) test for the identification of blood-meals of haematophagous insects. Bulletin of Entomology Research, v. 76, p. 321-330, 1986.

SHANNON, R.C. Methods for collecting and feeding mosquitoes in jungle yellow fever studies. American Journal of Topical Medicine, v. 19, p. 131-138, 1939.

SILVA, D.A. da. Aspectos ecológicos da fauna flebotomínea (Díptera, Psychodidae) e suas implicações na epidemiologia das leishmanioses em Cotia, Estado de São Paulo, Brasil. 2005. 77 p. Dissertação (Mestrado em Epidemiologia) - Faculdade de Saúde Pública da Universidade de São Paulo, São Paulo, 2006.

SUDIA, W.D.; CHAMBERLAIN, R.W. Battery operated light trap an improved model. Mosquito News, v. 22, p. 126-129, 1962.

TANG, J.; UNNACH, T.R. Discriminating PCR artifacts using directed heteroduplex analysis (DHDA). Bio Techniques, v. 19, n. 6, p. 902-905, dez. 1995.

TEMPELIS, C.H. Host-feeding patterns of mosquitoes, with a review of advances in analysis of blood meals by serology. Journal of Medical Entomology, v. 11, n. 6, p. 635-653, jan. 1975.

TORINA A. et al. Use of phlebotomine sand flies as indicator of Leishmania prevalence in an endemic area. Ann N Y Acad Sci. n.1149 p. 355-357, dec. 2008.

VAN HANDEL, E. Metabolism of nutrients in the adult mosquito. Moquito News, v. 40, n. 4, p. 573-579, 1984.

VAZ, Celidéia A. Coppi. Interação antígeno-anticorpo "in vitro". In: CALICH, Vera Lúcia G.; VAZ, Celidéia A. Coppi. Imunologia básica. São Paulo: Editora Artes Médicas, 1988. Capítulo 7. p. 123-175.

VICENTIN, Elaine Cristina. Determinação pelo teste ELISA indireto da origem de sangue ingerido de Aedes scapularis coletados no Parque Ecológico do Tietê (PET), Estado de São Paulo. 2006. 125 p. Dissertação (Mestrado em Epidemiologia) - Faculdade de Saúde Pública da Universidade de São Paulo, São Paulo, 2006.

WEITZ, B. Feeding habits of bloodsucking arthropods. Experimental Parasitology, v. 9, p. 63-82, 1960.

YAGHOOBI-ERSHADI, M.R.; JAVADIAN, E.; KANNANI, A. Host preference pattern of phlebomine sandflies of Bokhar rural district, Isfahan province, Iran. Acta Tropica, V. 60, n. 3, p. 155-158, dez. 1995. 


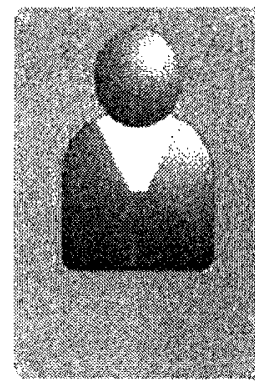

\section{Eunice Aparecida Bianchi Galati}

Possui graduaçáo em Ciências Biológicas pela Universidade de São Paulo (1977). graduaçăo em Ciências pela Universidade de São Paulo (1976), mestrado em Saude Pública pela Universidade de Sảo Paulo (1981), doutorado em Saúde Pública pela Universidade de São Paulo (1990) e livre-docéncia pela Universidade de São Paulo (2008). Atualmente é professor associado da Faculdade de Saúde Pública/USP.Tem experiencia de pesquisa e orientaçáo na área de Zoologia, com ênfase em Entomologia Médica (Diptera: Psychodidae, Phlebotominae) atuando principalmente em taxonomia e ecologia de flebotomíneos, bem como na epidemiologia de doenças veiculadas por vetores, sobretudo as leishmanioses. Desenvolveu projetos sobre flebotomineos de cavernas das Provincias Espeleológicas da Bodoquena e do Vale do Ribeira.

(Texto intormado pelo autor)

Última atualização do curriculo em 01/10/2008 Endereço para acessar este $\mathrm{CV}$ : http $/$ hattes.cnpq.br/1359035734723864

Dados pessoais

Nome Eunice Aparecida Bianchi Galati

Nome em cltações GALATI, E. A. B.

bibliograficas

Sexo Feminino

Endereço profissional Universidade de São Paulo, Faculdade de Saúde Publica, Departamento de Epidemiologia.

Av. Dr. Arnaldo, 715

Cerqueira Cesar

01246-904 - Sao Paulo, SP - Brasil

Telefone: (11) 30667786 Ramal: 011 Fax: (11) 30812108

\section{Formaçăo academica/Titulação}

2008 Livre-docéncia.

Universidade de Säo Paulo, USP, Brasll.

Título: Flebolomineos (Diptera, Psychodidae) da Provincia Espeleológica do Vale do Ribeira, Estado de Säo

Paulo, Brasil, Ano de obtençăo: 2008.

Palavras-chave: cavernas; dispersão; Ecologia de vetores; Fauna flebotominea; Leishmanioses; ambiente antrópico.

Grande área: Ciências Biológicas / Área: Parasitologia / Subárea: Entomologia e Malacologia de Parasitos e Vetores.

Grande área: Ciéncias Biológicas / Area: Zoologia / Subarea: Taxonomia dos Grupos Recentes / Especialidado:

Entomologia Médica.

Grande área: Ciências Biológicas / Área: Ecologia / Subárea: Ecologia de Vetores.

Setores de atividade: Saúde e Serviços Sociais.

1983 - 1990 Doutorado em Saúde Pública (Conceito CAPES 5)

Universidade de São Paulo, USP, Brasil.

Título: Sistemática dos Phlebotominae (Diptera, Psychodidae) das Américas, Ano de Obtençào: 1990.

Orientador: Ubirajara Ribeiro Martins de Souza.

Palavras-chave: Sistemática; Psychodidae; Taxonomia; Phlebotominae; Diptera.

Grande área: Ciências Biológicas / Area: Zoologia / Subárea: Taxonomia dos Grupos Recentes / Especialidade Entomologia Médica.

Setores de atividade: Saúde humana.

1979 - 1981 Mestrado em Saúde Pública (Conceito CAPES 5)

Universidade de Säo Paulo, USP, Brasil.

Título: Aspectos taxonômicos e biogeográficos do género Psychodopygus Mangabeira, 1941 e sua importància epidemiológica (Diptera, Phlebotominae), Ano de Obtençâo: 1981.

Orientador: Oswaido Paulo Forattini.

Palavras-chave: Taxonomia; Biogeografia; Diptera; Phlebotominae; Psychodopygus.

Grande área: Ciências Biológicas / Area: Zoologia / Subárea: Taxonomia dos Grupos Recentes / Especialidade Entomologia Médica.

Setores de atividade: Saúde humana.

1978 - 1978 Especializaçăo em Curso de Especialização Em Saúde Pública . (Carga Horária: 978h). Universidade de Săo Paulo, USP, Brasil.

1972 - 1977 Graduaçăo em Ciências Biológicas

Universidade de Såo Paulo, USP, Brasil.

1972 - 1976 Graduação em Ciências

Universidade de Såo Paulo, USP, Brasil.

1970 - 1970 Curso técnico/profissionalizante em Epidemiologia Médico Entomológica Universidade de São Paulo, USP, Brasil.

\section{Atuaçăo profissiona:}

Universidade de Såo Paulo, USP, Brasil.

Vinculo institucional 


\section{Iole Arumi Sei}

Possui graduação em Ciências Biológicas pela Universidade de Mogi das Cruzes (1998). Mestranda em Saúde Pública área de concentração Epidemiologia pela Faculdade de Saúde Pública da Universidade de São Paulo (2007). Técnico de Apoio a Pesquisa Clentífica e Tecnológlca da Superintendência de Controle de Endemias. Tem experiência na área de Saúde Coletiva, com énfase em Epidemiologia, Imunoepidemiologia atuando principalmente nos seguintes temas: Doença de Chagas, Malária, Esquistossomose, Leishmaniose e Programa de Controle.

(Texto informado pelo autor)

Uitima atualização do currículo em 07/01/2009

Endereço para acessar este CV:

http://attes.cnpq.br/4496398419371370

Dados pessoais

Nome lole Arumi Sei

Nome em citaçöes SEI, I. A.

bibliográticas

Sexo Feminino

Enderoco profissional Superintendência de Controle de Endemias.

Rua Paula Souza, 166 Laboratório de Soroepidemiologia $5^{\circ}$ andar

Luz

$01027-000$ - Sao Paulo, SP - Brasil

Telefone: (011) 33111178 Fax: (011) 33111192

URL da Homepage: htto:/buscatextual.cnpa.br/buscatextual/www.sucen.so.gov.br

Formação acadêmica/Titulação

2007 Mestrado em andamento em Saúde Pública .

Faculdade de Saúde Pública da Universidade de São Paulo, FSP/USP, Brasil

Titulo: Dípteros da Subfamilia Phlebotominae: uso da técnica imunoenzimática (ELISA) para deteccão de fontes alimentares sangüíneas., Orientador: Eunice Aparecida Bianchi Galati

Palavras-chave: Epidemiologia; Doenças transmissiveis por vetores; Estudo da morfologia de flebotomineos;

Estudo de infecçăo natural de flebotomíneos; Identificaçăo de flebotomineos; Leishmaniose Tegumentar Americana.

Grande área: Ciências da Saúde / Área: Saúde Coletiva / Subárea: Epidemiologia.

Grande área: Ciências da Saúde / Area: Saúde Coletiva / Subárea: Saúde Pública.

Setores de atividade: Saúde e Serviços Sociais.

1994 - 1998 Graduação em Ciências Biológicas

Universidade de Mogi das Cruzes, UMC, Brasil.

Formação complementar

2006 - 2006 Preparação, produção purificação de proteinaas. (Carga horaria: 160h). Universidade de Säo Paulo, USP/ICB, Brasil.

2006 - 2006 Téc de infecçăo de Biomphalarias, animais em lab.. (Carga horária: 80h). Instituto Adolfo Lutz, IAL, Brasil.

2004 - 2004 Diagnóstico molecular de malária. (Carga horária: 80h). Superintendência de Controle de Endemias, SUCEN, Brasil.

2004 - 2004 colheita de sangue digital absorvido em papel-fil. (Carga horária: 80h). Superintendéncia de Controle de Endemias, SUCEN, Brasil.

2003 - 2003 Estágio no Laboratório de Flebotomíneos. (Carga horária: 80h). Faculdade de Saúde Pública, FSP, Brasil.

2001 - 2001 Téc. e Monitoramento de Controle Químico de Inseto. (Carga horária: 60h) Universidade Federal do Rio de Janeiro, UFRJ, Brasil.

2000 - 2000 Epidemiologia das doenças transmissiveis. (Carga horária: $32 \mathrm{~h}$ ) Faculdade de Saúde Pública da Universidade de São Paulo. FSPiUSP. Brasil.

\section{Atuaça profissiona:}

\section{Superintendencia de Controle de Endemias, SUCEN, Brasil}

\section{Vinculo instituciona}

1994 - Atual Vínculo: Servidor Público, Enquadramento Funcional: Téc. Apoio a pesquisa Científica Tecnológica, Carga horária: 40, Regime: Dedicaçäo exclusiva 